\title{
La carrera eclesiástica de Juan Francisco Muñoz y Pabón en el Seminario Conciliar de Sevilla
}

\author{
Manuel Martín Riego \\ Centro de Estudios Teológicos - Sevilla
}

\begin{abstract}
Resumen: Este trabajo de investigación nace con motivo del 150 aniversario del nacimiento del canónigo doctor Juan Francisco Muñoz y Pabón (1866-1920), estudiante (1878-1893) y posteriormente profesor (1887-1920). Ofrecemos una visión general del seminario conciliar de San Isidoro y San Francisco Javier de Sevilla desde su erección en 1831 en Sanlúcar de Barrameda hasta la creación de la universidad pontificia en 1897. La vida cotidiana -estudios y religiosidad- está muy presente en este artículo. La parte central del mismo está dedicada a nuestro biografiado Muñoz y Pabón: seminarista, sacerdote, profesor y canónigo. Este trabajo finaliza con dos apéndices: el primero sobre el claustro de profesores del seminario (1878-1920) y el segundo sobre el colegio de doctores de la facultad de teología de la universidad pontificia de Sevilla (1897-1931).
\end{abstract}

\begin{abstract}
This research paper deals with the 150 anniversary of the birth of Canon Dr. Juan Francisco Miñoz y Pabon (1866-1920), who was student (1878-1893) and later professor (1887-1920). We offer a general view of Sevillian Diocesan Seminary named S. Isidoro and S. Francisco Javier, starting with its foundation in 1831 at Sanlucar de Barrameda, until its creation as Pontifical University in 1897. Seminar's daily life -studies and religiosity- is very present in this paper. The main part from it is dedicated to our biographer Muñoz y Pabon: seminarian, priest, professor and Canon. This work ends with two annexes: the first one regarding the Seminary staff of professors (1878-1920) and the second one is about the Doctoral Staff from the Theology Faculty at Pontifical University of Seville. (1897-1931).
\end{abstract}

\section{INTRODUCCIÓN}

El 16 de junio de 1866 nacía en Hinojos, provincia de Huelva y diócesis de Sevilla en aquella época, el doctor en teología Juan Francisco Muñoz y Pabón, canónigo y profesor del seminario de San Isidoro y San Francisco Javier. Estamos, 
por tanto, en el ciento cincuenta aniversario de su nacimiento. Con motivo de este acontecimiento, hemos realizado este trabajo de investigación en el que nos acercamos a su figura y carrera eclesiástica como profesor y sacerdote.

En un primer momento damos una visión general del seminario conciliar de Sevilla desde su erección en Sanlúcar de Barrameda, instalación en el edificio Maese Rodrigo de Sevilla y la creación de la universidad de Sevilla en 1897. En esta realidad vivió toda su vida como estudiante desde el curso 1878-79 y profesor desde 1887 hasta 1920. Recreamos la vida cotidiana y la religiosidad de los seminaristas en la época en la que residió en el seminario.

Planes de estudios, asignaturas, programas de asignaturas, libros de textos, exámenes, seminaristas, profesores estarán presentes en nuestro estudio. Un aspecto a destacar es la religiosidad y vida y actos de piedad en el seminario.

Como parte central de este trabajo ofrecemos una breve biografía de Muñoz y Pabón, siempre en su relación con el seminario de San Isidoro y San Francisco Javier, posteriormente pontificio con motivo de la creación de la universidad pontificia de la que formó parte nuestro ilustre biografiado: nacimiento y familia, entrada en el seminario, curriculum académico en humanidades, teología y cánones, órdenes sagradas, profesor y carrera eclesiástica.

El artículo finaliza con dos apéndices. El primero recoge la relación de todos los profesores que enseñaron en el seminario de Sevilla tanto en humanidades como en teología y cánones, la mayor parte de ellos profesores y superiores de nuestro biografiado. También el listado de todos los que formaron el claustro y fueron compañeros de Muñoz y Pabón como enseñante. El segundo ofrece la relación de todos los que formaron el colegio de doctores de la facultad de teología de la universidad pontificia entre 1897 y 1931.

\section{EL SEMINARIO CONCILIAR DE SEVILLA}

\subsection{El Seminario de Sevilla en Sanlúcar de Barrameda}

El seminario conciliar de Sevilla fue erigido en 1831 en Sanlúcar de Barrameda bajo la advocación de San Francisco Javier, en honor del prelado que lo creaba, el cardenal Francisco Javier Cienfuegos y Jovellanos (1825-1847), y del fallecido fundador Francisco de Paula Rodríguez Berdejo, natural de Sevilla y vecino de Sanlúcar de Barrameda ${ }^{1}$.

Los estatutos del seminario conciliar fueron aprobados por el cardenal Cienfuegos el 1 de septiembre de 1831. Contienen 33 títulos y 254 artículos. En ellos se abordan los más variados aspectos de la vida de los colegiales: órganos de gobierno, organización de los estudios, métodos de enseñanza, exámenes,

M. MARTÍN RIEGO, La formación intelectual del clero. El seminario conciliar de Sevilla (1831-1931), Sevilla, 49-79. 
vestidos, pautas de comportamiento, castigos, visitas, vacaciones, jornada diaria, religiosidad, etc. ${ }^{2}$

El seminario tuvo una existencia efímera en Sanlúcar. La real orden del 23 de abril de 1842 ordenaba al gobernador eclesiástico devolver los bienes de la fundación Francisco de Paula a la Junta inspectora para la creación de un instituto de segunda enseñanza en Sanlúcar. El seminario cerró sus puertas en junio de 1842, quedándose la diócesis sin esta institución, básica para la formación del clero³

\subsection{El Seminario en el edificio de Maese Rodrigo}

En 1846 el gobernador eclesiástico del arzobispado de Sevilla había solicitado de S. M. la erección del seminario en Sevilla y ya se le había incluido en los presupuestos de culto y clero. Solamente faltaba la designación del local. Con fecha 2 de marzo de 1847 se pone a disposición de la diócesis el edificio llamado Maese Rodrigo, antiguo colegio de Santa María de Jesús y universidad de Sevilla.

La autoridad eclesiástica tomó posesión del edificio de la Puerta de Jerez, llamado Maese Rodrigo Fernández de Santaella, el 23 de mayo de 1847. El seminario de Sevilla abrió sus puertas el 1 de octubre de 1848, bajo la advocación de San Isidoro y San Francisco Javier, después de haberse realizado una obra presupuestada en 112.349 reales. Acaba de tomar posesión de la sede el arzobispo Judas José Romo y Gamboa (1848-1855), pasando a ser en la historia de la Iglesia de Sevilla el prelado que erigió el seminario ${ }^{4}$.

El seminario llevó a cabo grandes reformas, ampliando su fábrica con la adquisición y agregación de edificios contiguos. Se compró la casa número 14 de la calle San Gregorio. A pesar de tantas obras y reparaciones, el edificio nunca reunió las condiciones para el elevado número de alumnos que albergaba. Estaba mal distribuido, carecía de jardines y lugares espaciosos para la recreación, era muy húmedo en invierno, cuartos y habitaciones sin ventilación, biblioteca muy deficiente, etc. Con las siguientes palabras se expresaba D. Silvestre Pérez Godoy, canónigo y rector del seminario en el discurso inaugural del curso 1888-89:

Para el adelanto en la enseñanza y el aprovechamiento en los estudios, le falta biblioteca, porque la que existe es muy incompleta y deficiente, como formada en tan pocos años y sin base alguna, y no con libros atinadamente elegidos, sino con los que prelados y sacerdotes han hecho la caridad de cederles. Le faltan además aulas independientes, capaces, iluminadas y ventiladas. Le falta asimismo mejorar y completar los gabinetes y

2 F. J. CIENFUEGOS JOVELLANOS, Estatutos del Seminario conciliar de San Francisco Javier en la ciudad de Sanlúcar de Barrameda, y Reglamento, Sevilla, 1831.

3 ARCHIVO GENERAL DEL SEMINARIO DE SEVILLA (Abreviado: AGSS.). Leg. 1. Papeles varios. Historia de las múltiples vicisitudes por las que ha pasado la fundación de Francisco de Paula Rodríguez en Sanlúcar de Barrameda desde 1811 a 1862. El archivo general del seminario de Sevilla se encuentra como archivo incorporado en el diocesano.

4 J. ALONSO MORGADO, Prelados sevillanos, Sevilla, 1899-1904, 797-798. 
poner su material científico a la altura de los adelantos modernos. Le falta, en fin, dotación para su personal, retribuido de una manera vergonzosamente mezquina.

Pero, sobre todo, para la moralidad, para la higiene, para la disciplina, le falta edificio de otra capacidad y condiciones... Y no pudiendo hoy la Iglesia, empobrecida y despojada, realizar esta mejora, tampoco puede elevar la educación sacerdotal a mayor altura, si la iniciativa privada no viene resueltamente en su auxilio ${ }^{5}$.

Fue una suerte que la infanta María Luisa cediera el Palacio de San Telmo al arzobispo de Sevilla en 1892. Después de las obras pertinentes para su nuevo uso como seminario conciliar, el curso 1901-02 se abrió en el Palacio de San Telmo. El edificio Maese Rodrigo fue vendido a Juan Bautista Calvi Rives por la cantidad de 252.500 pesetas, pagaderas en cuatro años ${ }^{6}$.

\subsection{La Universidad Pontificia}

\subsubsection{Breve historia}

A raíz del concordato de 1851, los seminarios conciliares de Toledo, Salamanca, Valencia y Granada se convirtieron en seminarios centrales. Podían conceder los grados mayores de licenciado y doctor en teología y cánones. Eran reconocidos por el Estado y la Santa Sede aceptaba dichos títulos académicos para los efectos eclesiásticos ${ }^{7}$. En 1876 se otorgó la categoría de centrales a los seminarios de Santiago de Compostela y Canarias. El de Sevilla fue excluido, concediendo solamente el grado de bachiller en teología y cánones ${ }^{8}$. En 1896 la Santa Sede concedió a los seminarios centrales de Toledo, Salamanca, Valencia, Granada y Santiago de Compostela la erección de tres facultades more universitario de filosofía escolástica, sagrada teología y derecho canónico. En años sucesivos fueron erigidas universidades pontificias en todos los seminarios de sede metropolitana.

Los arzobispos de Sevilla desde Tarancón y Morón (1857-1862) a Spínola (1896-1906) habían solicitado el título de central para el de Sevilla con el objetivo de poder conferir grados mayores en teología, y derecho canónico. Todas las gestiones habían resultado inútiles ${ }^{9}$. El 8 de septiembre de 1896 el

5 BOLETÍN OFICIAL DEL ARZOBISPADO DE SEVILLA (Abreviado: BOAS). S. PÉREZ GODOY, "Discurso leído en el seminario conciliar de Sevilla en la solemne inauguración del curso académico 1888-89", BOAS 142 (1888) 434-439.

6 AGSS. Libro 81. Cuentas generales de cargo y data del seminario de San Isidoro y San Francisco Javier de Sevilla. Años 1865-1912.

7 V. CÁRCEL ORTÍ, "La Universidad Pontificia de Valencia (1896-1931)”, Hispania Sacra 22 (Madrid 1969) 287-331; A. MARTÍN MELQUÍADES, "Las facultades de teología en las universidades españolas (1396-1868)", Revista Española de Teología 28 (Madrid 1968) 346; M. MARTÍN RIEGO, "La universidad pontificia de Sevilla", Isidorianum 2 (Sevilla 1992) 223-262,

8 AGSS. Libro 65. Libro primero de asiento de los grados de bachiller en teología y derecho canónico desde 1848 a 1897. Hay registrados 83 títulos de bachillerato en teología y 9 en derecho canónico.

9 Erectio Apostolica Facultatum Sacrae Theologiae, Iuris Canonici et Philosophiae Scholasticae in Seminario Hispalensi (Hispali 1897) 3-8. 
arzobispo Spínola expone a León XIII la situación de inferioridad en la que se encuentra la archidiócesis hispalense con respecto a las sedes que gozan de seminarios centrales. Hace un breve excursus sobre los títulos que adornan a la Iglesia de Sevilla, remontándose a la figura de San Isidoro. Asimismo le expresa la importancia de la ciudad de Sevilla por sus monumentos, instituciones universitarias, militares, academias, etc. Pone especial énfasis en recalcar las dificultades materiales del clero hispalense para estudiar un bienio en la pontificia universidad de Granada con el fin de obtener grados mayores. Por último, le manifiesta que las prebendas de la catedral y de las parroquias serían obtenidas por clero extradiocesano con grave lesión para los sacerdotes de su diócesis ${ }^{10}$.

El cardenal Mazella, prefecto de la Sagrada Congregación de Estudios, responde al arzobispo el 6 de octubre de 1896 y le indica la Congregación se reunirá el 12 de noviembre y tratará su petición. Mientras tanto, debe pedir al nuncio la instrucción Quum Apostolicum de 30 de julio de 1896, dirigida a los prelados de Valencia. Toledo, Santiago de Compostela, Granada y Salamanca. Siguiendo estas normas, debe confeccionar unos estatutos para el seminario de Sevilla con el fin de que se le pueda conceder la erección de las facultades ${ }^{11}$.

La Sagrada Congregación de Estudios en su reunión de 1 de julio de 1897 concedió al seminario de Sevilla las tres facultades y aprobó sus estatutos por espacio de diez años. El decreto de erección tiene fecha de 4 de agosto de 1897 y está firmado por el cardenal Satolli, prefecto de dicha Congregación. El arzobispo hizo pública la noticia en el boletín oficial del arzobispado, insertando todos los trámites realizados, los estatutos, los colegios de doctores, la confirmación de los profesores y la ratio studiorum ${ }^{12}$. Este acontecimiento, trascendental para la formación intelectual del clero hispalense, fue celebrado en el seminario con solemnidad. Una vez instalada la Universidad Pontificia en el Palacio de San Telmo, en el claustro central y al lado izquierdo de la entrada en la capilla se colocó una lápida conmemorativa con la siguiente inscripción.

\author{
LEONI XIII \\ SEMINARIAUM HISPELENSE \\ IN PONTIFICIAM UNIVERSITATEM \\ PRECIBUS \\ D. D. MARCELLI SPINOLA MAESTRE \\ PREAECLARI ANTISTITIS \\ SUB AN MDCCCXCVII \\ EVEHENTI \\ ACADEMICUS ORDO PERGRATUS
}

N. D. D.

Ibid. 9-13.

Ibid. 15-16.

BOAS. N- 372 (1897) 146-190; AGSS. Leg. 7. Documentos sobre la Universidad Pontificia. 


\section{LA JORNADA DIARIA}

La vida cotidiana de los seminaristas tenía como ejes centrales las horas dedicadas al estudio y a la vida religiosa. En torno a estas dos coordenadas se configuraban todas las otras actividades del seminario. Un análisis del horario, tanto en los días laborables como en los festivos, nos permite acercarnos al discurrir de los días en este centro ${ }^{13}$.

\subsection{Días laborables}

La jornada de los días laborables, según podemos observar en el horario adjunto, era muy apretada y toda ella giraba en torno a los actos de piedad y a las actividades escolares: clases y estudio personal.

\section{HORARIO DE LOS DÍAS LABORABLES}

\begin{tabular}{|l|l|}
\hline HORA & ACTIVIDAD \\
\hline $5^{\prime} 30$ & Levantarse. Aseo \\
\hline $5^{\prime} 55$ & Ofrecimiento de obras y meditación \\
\hline $6^{\prime} 30$ & Santa Misa. Desayuno \\
\hline $7^{\prime} 30$ & Estudio \\
\hline 9 & $\begin{array}{l}\text { Clases y estudio (los latinos tendrán clase hasta las diez y media y después } \\
\text { recreo de un cuarto de hora) }\end{array}$ \\
\hline $12^{\prime} 30$ & $\begin{array}{l}\text { Comida con lectura instructiva (los domingos y días festivos no habrá } \\
\text { lectura al mediodía) }\end{array}$ \\
\hline $13^{\prime} 10$ & Visita al Santísimo Sacramento y recreo \\
\hline $14^{\prime} 15$ & Estudio general \\
\hline 16 & Clases (los latinos tendrán clase desde las tres y media) \\
\hline 17 & $\begin{array}{l}\text { Merienda y recreo (se recomienda a los alumnos visitar al Santísimo durante } \\
\text { el recreo) }\end{array}$ \\
\hline 18 & Estudio (confesiones durante el estudio) \\
\hline $20^{\prime} 15$ & Santo Rosario y lectura espiritual \\
\hline $20^{\prime} 45$ & Cena con lectura. Recreo \\
\hline $21^{\prime} 30$ & $\begin{array}{l}\text { Examen de conciencia y lectura de los puntos para la meditación del día } \\
\text { siguiente. }\end{array}$ \\
\hline $21^{\prime} 45$ & Descanso (a las diez han de apagarse todas las luces de los cuartos). \\
\hline
\end{tabular}

13 M. MARTÍN RIEGO, La formación intelectual del clero. El seminario..., o. cit., 216-220. 
El día comenzaba con el ofrecimiento de obras y la meditación y finalizaba con el examen de conciencia y la preparación de la meditación del día siguiente. Media hora antes de levantarse los alumnos lo hacían los fámulos para llamar a las cinco y media de la mañana a toda la comunidad del seminario. Las horas dedicadas a las clases eran tres -dos por la mañana y una por la tarde-. El tiempo dedicado al estudio giraba en torno a las seis horas y media y el del descanso nocturno sobre las ocho horas. Se pretendía que los seminaristas adquirieran "un decidido amor al estudio, tan necesario para los que han de enseñar a los pueblos". Los recreos aparecen como espacios de sano esparcimiento después del estudio y de las comidas. Se trata de un horario bastante rígido, demasiado cargado, severo y muy largo, sobre todo si pensamos en la corta edad de los alumnos de los primeros cursos de humanidades. No es de extrañar que los problemas de indisciplina fueran corrientes y que muchos estudiantes abandonaran el seminario, no siempre por falta de vocación, sino frecuentemente por no poder soportar un horario tan espartano. Los alumnos externos, como es obvio, no seguían este horario. Solamente se limitaban a asistir a las clases, cumpliendo con los actos de piedad en sus respectivas parroquias.

Durante la comida de los días lectivos se tenía lecturas instructivas: el Boletín oficial del arzobispado, el Mensajero del Sagrado Corazón de Jesús, historia de la Iglesia, etc. Durante la cena de los mismos días se hacía lectura de tipo espiritual: vida de santos o las obras de Fr. Luis de Granada. En el tiempo de cuaresma se tenía el sermón via exercitii tres días por semana en la cena.

La jornada de los jueves lectivos era distinta. Si no se celebraban academias, el horario era igual por la mañana. Si se celebraban academias, las clases eran suspendidas. Después del desayuno había hora y media de estudio y a las diez y treinta empezaban las academias hasta las doce. Recreo y comida. A las dos de la tarde comenzaban las conferencias para todos los alumnos: científicoreligiosas para los seminaristas e los cuatro últimos años de teología y para los canonistas, de disciplina y urbanidad para los restantes alumnos del seminario mayor y de catecismo para los del seminario menor. Se concluía con una visita al Santísimo y se procedía al paseo, regresando los estudiantes para la merienda y a las seis y media de la tarde comenzaba el estudio y a partir de esta hora se seguía el horario diario.

\subsection{Domingos y festivos}

Los domingos y días festivos, como es natural, la jornada era distinta, según podemos observar en el siguiente cuadro adjunto. 


\section{HORARIO DE DOMINGOS Y DÍAS FESTIVOS}

\begin{tabular}{|l|l|}
\hline HORA & ACTIVIDAD \\
\hline 6 & Levantarse \\
\hline $6^{\prime} 25$ & Ofrecimiento de obras y meditación \\
\hline 7 & Santa Misa y comunión obligatoria para todos \\
\hline 8 & Desayuno \\
\hline 9 & Aseo y estudio \\
\hline 11 & $\begin{array}{l}\text { Catecismo, urbanidad y canto gregoriano, respectivamente para latinos, } \\
\text { filósofos y teólogos solo los domingos }\end{array}$ \\
\hline $11^{\prime} 45$ & Recreo y visitas \\
\hline $12^{\prime} 30$ & Comida \\
\hline $13^{\prime} 15$ & $\begin{array}{l}\text { Visita al Santísimo Sacramento y recreo (visita de los parientes en primer y } \\
\text { segundo grado) }\end{array}$ \\
\hline $14^{\prime} 30$ & Canto de Vísperas \\
\hline 15 & Paseo. A la vuelta merienda y recreo \\
\hline 18 & Estudio (los días festivos solemnes recreo extraordinario) \\
\hline 20 & Santo Rosario, plática y bendición con el Santísimo \\
\hline $20^{\prime} 45$ & Cena \\
\hline $21^{\prime} 30$ & $\begin{array}{l}\text { Examen de conciencia y lectura de puntos para la meditación del día } \\
\text { siguiente }\end{array}$ \\
\hline $21^{\prime} 45$ & Descanso (a las diez han de apagarse todas las luces de los cuartos) \\
\hline & \\
\hline 19
\end{tabular}

En el horario de los días festivos, como es lógico, el tiempo dedicado al descanso y a la recreación es más amplio. No obstante, determinadas horas se reservaban al estudio y a la formación humana y cristiana. El momento más importante del día era la Misa cantada, obligatoria para toda la comunidad del seminario y para los alumnos externos. Los domingos y festivos eran los días propios para que los padres y parientes cercanos visitasen a sus familiares seminaristas.

Los estatutos de 1884 incorporan algunos leves cambios en el horario sobre todo en las mañanas de los jueves. También en la distribución del tiempo y actividades de los fámulos ${ }^{14}$. En relación al horario, los estatutos de 1884

14 Algunos seminaristas pobres realizaban determinados servicios y con ello sufragaban todos los gastos de la pensión. Recibían el nombre de fámulos, ya que eran servidores del seminario. La provisión de dichas plazas correspondía al prelado. Para conseguir una plaza de fámulo había que ser previamente alumno del seminario y de la segunda sección (los pobres), natural de la diócesis, cursar filosofía o teología, nota de Benemeritus en todas y cada una de las asignaturas del curso anterior y mostrar reconocida moralidad y vocación eclesiástica. 
modifican la jornada de los jueves, dedicando la mañana al estudio y a las academias. Por la tarde conferencias disciplinares y estudio. Los actos de piedad y religiosos eran los mismos.

\section{LA RELIGIOSIDAD}

El fin se los seminarios es la formación de buenos ministros de la Iglesia que, llenos de celo sacerdotal y dotados de la ciencia necesaria, trabajen eficazmente por la gloria de Dios y la salvación de las almas. De aquí la importancia que los estatutos conceden a la vida religiosa y espiritual en el seminario.

\subsection{La vida de piedad en el seminario}

No cabe duda que estamos delante del primordial objetivo de la fundación de los seminarios conciliares. La piedad, podemos decir, es la médula de la educación eclesiástica. Sin ella, la formación del seminario estaría totalmente vacía y en nada se distinguiría de otro centro de estudios. Si la finalidad del seminario es que el aspirante al sacerdocio se identifique con Cristo, sacerdos alter Christus, nada tiene de particular que la piedad informe la vida cotidiana del seminario. Para conseguir esta perfección fueron instituidos los seminarios y a ello deben tender, como lo demuestra la práctica constante de la Iglesia, al someter a los seminaristas a una preparación tan larga ${ }^{15}$.

Los diversos estatutos del seminario de Sevilla dan una importancia primordial a la formación espiritual y religiosa de sus alumnos. El rector, el director espiritual y los superiores deben cuidar de esta formación y procurarán con "todo esmero que sean educados en la piedad sólida y que adquieran verdadero espíritu eclesiástico, disponiéndose así para el sagrado ministerio del altar y de la Iglesia"16.

La vida cotidiana del seminario debe estar llena de este espíritu religioso y en la formación espiritual de los seminaristas debe ocupar un lugar preferente la ascética cristiana. En este aspecto, el seminario debe ser"una escuela práctica de verdadera formación espiritual"17. La vida sobrenatural debe informar toda la jornada del seminario. Un instrumento básico para lograr estos objetivos lo constituyen las prácticas religiosas y los actos de piedad que serán los goznes y pilares de la formación seminarística.

15 C. SÁNCHEZ ALISEDA, La doctrina de la Iglesia sobre Seminarios desde Trento hasta nuestros días, Granada, 1942, 154-170; L. GARCÍA GARCÍA, El aspirante al sacerdocio y su formación. Vol. II, Salamanca, 1947, 295-321; G. MARTIL. "Problemas actuales de la formación espiritual de los seminaristas", Seminarios 10, Salamanca, 1964, 57-80; J. FLORES MARTÍN, "Espiritualidad sacerdotal y seminario", Seminarios 10, Salamanca, 1964, 81-98.

16 E. ILUNDÁIN ESTEBAN, Reglamento del Seminario General y Pontificio de San Isidoro y San Francisco Javier de Sevilla, Sevilla, 1924, 47.

17 Ibidem. 


\subsection{Los actos de piedad}

La vida cotidiana del seminario, como hemos visto en el horario, está vertebrada desde los actos de piedad. Los estatutos de 1831 y 1884 reglamentan hasta los aspectos más nimios de la vida espiritual y religiosa del seminario. Entre estas prácticas tenemos las cotidianas, las semanales, las mensuales y las anuales.

Entre las cotidianas figuran las siguientes: ejercicio cristiano de la mañana; media hora de meditación; misa, precedida de la comunión; visita al Santísimo; rezo del rosario; un cuarto de hora de lectura espiritual; examen de conciencia; lectura de los puntos para la meditación del día siguiente y las preces de la noche. Además, en el desarrollo de otras actividades cotidianas también está presente la oración: al iniciar las clases, al bendecir la mesa y dar gracias a Dios por los alimentos, en las lecturas piadosas en el comedor, etc. Se pretende que el seminarista esté constantemente en presencia de Dios.

Entre los actos de piedad semanales podemos enumerar los siguientes: bendición con el Santísimo todos los jueves; canto de la Salve en honor de la Virgen todos los sábados y vísperas de fiestas marianas; misa cantada para toda la comunidad del seminario todos los domingos y festivos; canto de tercia en los días solemnes; canto de vísperas todas las tardes de los domingos y días festivos; bendición con el Santísimo y plática del director espiritual todos los domingos y festivos antes de la cena. También se recomienda la confesión frecuente, semanal o quincenal.

Todos los meses tenían los seminaristas un retiro espiritual. Si el día elegido por el rector era festivo, el retiro se iniciaba por la noche para finalizarlo al día siguiente a las dos y media de la tarde. Si el día era laborable, comenzaba a las once de la mañana hasta la hora de acostarse. El retiro constaba de una o dos pláticas, además de los actos de piedad propios de estos días. Asistían los alumnos internos y los externos. Todos los domingos primeros de cada mes se celebraba el ejercicio solemne en honor del Sagrado Corazón. Este acto religioso estaba formado por las siguientes prácticas: exposición solemne y bendición con el Santísimo, rosario, consagración, desagravio y plática. Asistían internos y externos.

Todos los meses tenemos ciertas prácticas de piedad, sobre todo novenas. En octubre la comunión reparadora semanal tanto para los internos como para los externos y el rezo del rosario con el sagrario abierto. En noviembre la novena a las almas del purgatorio, los maitines de difuntos el día uno y misa cantada de réquiem solemne el día de la conmemoración de los fieles difuntos. En diciembre la solemne novena a la Inmaculada y la del Niño Jesús.

La cuaresma y la semana santa eran momentos ideales para incrementar los ejercicios de piedad. Triduo durante el carnaval con comunión, misa cantada y exposición del Santísimo todo el día y procesión claustral el último día. Plática 
durante las tres tardes. Asistían todos los alumnos del seminario. Todos los viernes de cuaresma el vía crucis cantado. La novena rezada a San José y el septenario de la Virgen de los Dolores con el Stabat Mater cantado. El miércoles y el jueves santo cantaba el seminario maitines y laudes del oficio del día.

Durante el mes de marzo, a partir del día 4, se tenía la novena rezada a San Francisco Javier. En mayo se practicaba el ejercicio diario de las Flores para los internos durante el rezo del rosario por la noche con una plática, ocupando la cátedra sagrada un ordenado in sacris los domingos y festivos de dicho mes. En junio, el día indicado por el rector, se celebraba una función en honor del Sagrado Corazón de Jesús con comunión, exposición mayor durante todo el día y el ejercicio solemne con sermón por la tarde para acabar con la procesión claustral.

Las festividades de la Inmaculada, Santo Tomás de Aquino, San Isidoro y San Francisco Javier eran celebradas con comunión, misa cantada y sermón. Los días de oficios pontificales de la catedral asistía el seminario a los mismos, siempre que se celebrasen en días festivos o de vacaciones literarias. El seminario también asistía a la solemne procesión del Corpus.

La organización de todos los actos religiosos era responsabilidad del director espiritual, siempre de acuerdo con el rector del seminario.

Entre las prácticas religiosas anuales estaban los ocho días de ejercicios espirituales en el tiempo designado por el prelado. En la época en que el seminario estuvo ubicado en el edificio Maese Rodrigo, los internos lo hacían en dicho lugar y los externos en la casa-hospital de los Venerables ${ }^{18}$. Cuando el seminario fue trasladado al Palacio de San Telmo todos los alumnos hacían aquí los ejercicios, incluso muchos sacerdotes. Los directores de los mismos solían ser jesuitas.

\subsection{Las asociaciones piadosas}

Entre las asociaciones piadosas que figuran en el seminario en la época de Muñoz y Pabón están la del Apostolado de la Oración y la de la Inmaculada y San Juan Berchmans.

La primera estaba presente en todos los seminarios españoles y era recomendada a los alumnos para desarrollar en ellos el espíritu de oración. En el seminario de Sevilla se estableció canónicamente el 20 de enero de 1884 por iniciativa deAntonio Ruiz-Cabal Rodríguezy de Juan CrisóstomoVacas González, rector y director espiritual del seminario, respectivamente. Entre sus objetivos figuraban: promover la práctica de la oración; fomentar el espíritu sobrenatural, la práctica de la virtud y el apostolado; orar asiduamente por las necesidades de la Iglesia; comunión reparadora semanal; rezar por los pecadores; alimentar

18 BOAS. N. 943 (1877) 327; AGSS. Libro 82. Libro segundo de cuentas generales de cargo y data del seminario conciliar de San Isidoro y San Francisco Javier. 
y desarrollar la vida interior; ofrecer a Dios los trabajos, fatigas y sufrimientos por las necesidades de la Iglesia; veneración al Santísimo; amor ferviente a la Virgen y, sobre todo, la devoción y el culto al Sagrado Corazón de Jesús. Se practicaban frecuentes actos de desagravios con la comunión reparadora, manifiestos, trisagios, visitas al Santísimo, los primeros viernes de mes y las horas santas. Con especial solemnidad se celebraba la fiesta del Corazón de Jesús. Como medios para inculcar esta devoción se recomendaba la práctica de los nueve primeros viernes de mes, los ofrecimientos de obsequios y el rezo del oficio parvo ${ }^{19}$.

La congregación de la Inmaculada y San Juan Berchmans estaba establecida canónicamente en la iglesia del Sagrado Corazón de Jesús de Sevilla y la dirigían los jesuitas. Un grupo de seminaristas empezó a frecuentar dicha congregación hasta que decidieron crear una sección. El seminario como tal entró a formar parte de dicha congregación en $1899^{20}$. En agosto del mismo año se constituyó la junta directiva y asistieron quince seminaristas, bajo la presidencia del jesuita Lara, fundador y primer director de la congregación. Poco a poco el número de seminaristas congregantes fue aumentando. Se reunían un domingo al mes. El padre Francisco Tarín fue el tercer director de esta congregación. La finalidad principal de esta asociación piadosa es la formación de verdaderos varones apostólicos. Los objetivos fundamentales son la devoción a la Virgen, el amor y la aplicación al estudio y el fomento de las virtudes cristianas y sacerdotales. Como medios para la consecución de estos fines tenemos los siguientes: la consagración a la Virgen y a San Juan Berchmans, modelo acabado del seminarista; la comunión mensual; pláticas piadosas; celebrar solemnemente las fiestas de la Inmaculada y San Juan Berchmans; visitar las cárceles y los hospitales y explicar el catecismo. Una vez ordenados de sacerdotes y destinados a la cura pastoral, seguían vinculados a la congregación.

\section{LOS RECTORES DEL SEMINARIO}

\subsection{Antonio Ruiz Cabal (1877-1884; 1885-1886)}

Había nacido en Villamartín el 4 de octubre de 1835. Fue el primer alumno matriculado en el seminario de Sevilla en el edificio de Maese Rodrigo en 1848. Aquí vistió la beca de colegial interno y estudió cuatro cursos de humanidades, tres de filosofía y siete de teología con cánones. En todas las asignaturas obtuvo la calificación de Meritissimus. En el seminario fue compañero de estudios de su hermano Juan, ordenado de tonsura el 17 de diciembre de 1858 a título de suficiencia ${ }^{21}$. Obtiene el bachillerato en teología el 5 de julio de 1858. Fue

AGSS. Libros 104 y 105. Libros de actas del Apostolado de la Oración (1901-1935).

AGSS. Libro 103. Libro de actas de la Congregación de María Inmaculada y San Juan Berchmans.

BOAS. N. 13 (1858) 201. 
ordenado de tonsura en la capilla del seminario y de presbítero el 24 de marzo de 1860, celebrando su primera misa en el seminario. Estudió derecho en la universidad literaria de Sevilla, consiguiendo el doctorado ${ }^{22}$.

Desempeñó el cargo de presidente de modernos y, tras la renuncia de Luis de los Ríos, presidente de antiguos, desempeñando este cargo desde el 30 de octubre de 1862. Posteriormente fue nombrado vicerrector y rector desde el 13 de diciembre de 1877, cargo que desempeñaba interinamente desde la promoción de Manuel González Sánchez como obispo auxiliar de Sevilla. Profesor de teología dogmática (1870-1876), de derecho público eclesiástico (1876-1887) y de decretales (1876-1887) ${ }^{23}$. Iniciador y promotor de la Obra Pía de San Isidoro para la educación de los seminaristas pobres, que más tarde erigió en institución permanente el arzobispo Lluch y Garriga. Bajo su rectorado se realizaron importantes obras en el edificio Maese Rodrigo. Canónigo doctoral, presidente de la sala de examinadores sinodales, juezpro-sinodal del arzobispado, examinador pro-sinodal para los concursos a curatos, fiscal del tribunal y visitador general del arzobispado y de los conventos de religiosas ${ }^{24}$.

La llegada a Sevilla del arzobispo Ceferino González supone para RuizCabal su cese como rector, ya que el prelado nombró para dicho cargo a su hermano Atanasio, licenciado en teología y deán de Segorbe, en febrero de 1884. Tras la renuncia de éste al cargo de rector el 8 de junio de 1885, fue nombrado de nuevo Ruiz-Cabal. Poco durará esta segunda etapa en el rectorado, ya que el 13 de mayo de 1886 fue presentado por la reina regente a laSanta Sede para el obispado de Pamplona. Fue consagrado el 22 de agosto y tomó posesión de su sede el 3 de septiembre de 1886.

Durante su pontificado en Pamplona edificó la capilla gótica en el claustro de la catedral, amplió el palacio episcopal, restauró la colegiata de Roncesvalles y se fundaron varios conventos masculinos y femeninos. Creó una Obra Pía para la dotación de diez doncellas pobres y varias becas para seminaristas pobres, además de edificar nuevas aulas en el seminario conciliar.

Por motivos de salud presentó su dimisión a León XIII y le fue admitida el 13 de diciembre de 1899, reteniendo la administración de su diócesis hasta la toma de posesión de su sucesor. Es nombrado obispo titular de Lystra, in partibus infidelium. Desde entonces fijó su residencia en Sevilla, ayudando a los prelados sevillanos en la administración de la confirmación y de las órdenes generales.

El obispo dimisionario de Pamplona y titular de Lystra había creado con sus propios bienes una fundación piadosa y perpetua en el seminario de

22 BOAS. N. 74 (1886) 408-410.

23 Datos tomados de los Boletines Oficiales del Arzobispado de Sevilla desde 1870 a 1887.

24 Estadística del clero del Arzobispado de Sevilla, Sevilla, 1880, 2-7. 
Sevilla con dos becas enteras y doce medias becas ${ }^{25}$. El capital de la fundación ascendía a 178.000 pesetas nominales en título de la deuda perpetua interior de España al 4 por ciento. Los réditos del capital pertenecían al fundador mientras viviera, comenzando a cumplirse la fundación con sus cargas desde el fallecimiento del mismo, consistente en 365 misas al año aplicadas por su intención y 750 pesetas anuales en favor de las necesidades del seminario. La fundación fue aprobada por el arzobispo de Sevilla el 20 de marzo de 1903. Su vida estuvo muy ligada al seminario sevillano, dejando una parte de su herencia a esta institución.

El obispo dimisionario de Pamplona y titular de Lystra falleció en Sevilla el 14 de octubre de 1908 y fue enterrado en la cripta de los arzobispos a petición del prelado y del cabildo catedralicio ${ }^{26}$.

Durante la primera etapa de rector del seminario de Sevilla de Antonio Ruiz-Cabal Rodríguez, Juan Francisco Muñoz y Pabón cursó los cuatro años de segunda enseñanza, el de ampliación y el de segundo de teología.

\subsection{Atanasio González Díaz Muñoz (1884-1885)}

Nacido en Villoria, perteneciente al Concejo de Laviana en la provincia de Oviedo. Vino a Sevilla al ser trasladado su hermano Ceferino de la sede de Córdoba a la hispalense. En febrero de 1884 es designado rector del seminario de Sevilla. Licenciado en teología y deán de la catedral de Segorbe. Le dio la toma de posesión el anterior rector Antonio Ruiz-Cabal Rodríguez, concurriendo al acto varios canónigos, el claustro de profesores y los seminaristas. Es nombrado canónigo de la catedral de Sevilla y dignidad maestreescuela. Al ser promovido el arzobispo Ceferino a la sede de Toledo, su hermano Atanasio renuncia al cargo de rector del seminario en junio de 1885. Juez pro-sinodal, obtiene el bachillerato en cánones en el seminario de Sevilla el 16 de mayo de $1889^{27}$.

Con este rector estudió primero de teología nuestro Juan Francisco Muñoz y Pabón.

\subsection{Silvestre Pérez Godoy (1886-1892)}

Nombrado rector del seminario en septiembre de 1886. Era canónigo lectoral de la catedral de Sevilla y doctor en teología. Bajo su época de rector se abrió el seminario menor en el antiguo convento de la Santísima Trinidad

25 ARCHIVO GENERAL DEL ARZOBISPADO DE SEVILLA (Abreviado: AGAS). Fondo Arzobispal. Sección II: Gobierno-Asuntos Despachados, nn. 441 y 460.

26 BOAS. N. 654 (1908) 419-423.

27 AGSS. Libro 65. Libro primero de asiento de los grados de bachiller en teología y derecho canónico desde 1848 a 1897. 
con esta advocación y la de Santo Tomás de Aquino ${ }^{28}$. Fue profesor de la asignatura Disciplina del concilio de Trento y particular de España, materia del séptimo curso de teología, desde 1890 a 1892. Pronunció en la inauguración del curso académico 1888-89 un famoso discurso sobre la institución de los seminarios conciliares, la historia del de Sevilla y su situación material y moral, haciendo especialmente alusión a las deficiencias del edificio de Maese Rodrigo ${ }^{29}$. Bajo su rectorado, el 3 de diciembre de 1890, se celebró el acto de consagración del seminario al Corazón de Jesús. La imagen fue realizada por el valenciano Gilabert.

El rector Pérez Godoy falleció en diciembre de 1892, tras una penosa enfermedad. Durante muchos años fue secretario de cámara y juez pro-sinodal. Con este rector estudió Muñoz y Pabón de tercero a sexto de teología.

\section{LOS PLANES DE ESTUDIO}

\subsection{Plan de estudios de 1852}

El concordato de 1851 supuso la total injerencia del poder civil en la organización de los estudios eclesiásticos. Los prelados eran los responsables de la disciplina interna y de la formación espiritual y moral de los seminaristas. El Estado, en definitiva, se arrogaba la facultad de organizar los estudios en los seminarios y de dictar los planes concretos

Con fecha 21 de mayo de 1852 Ventura González Romero, de acuerdo con el nuncio y los obispos españoles, publicó dos decretos: uno suprimiendo las facultades de teología en las universidades y otro sobre la enseñanza en los seminarios conciliares. El 28 de septiembre de 1852 la reina aprueba el plan de estudios de los seminarios. La real cédula consta de tres partes: introducción, plan de estudios y libros de texto ${ }^{30}$. En dicho plan, con algunos retoques, se formaron los clérigos españoles de la segunda mitad del siglo XIX hasta la creación de las universidades pontificias.

\subsubsection{Latinidad y humanidades}

El estudio de las humanidades constaba de cuatro cursos. Se suponía un elemental conocimiento del latín y del castellano, debiendo el candidato examinarse antes de ingresar en el seminario. Las asignaturas estudiadas en los cuatro cursos de humanidades quedan reflejadas en el siguiente cuadro.

28 Contaba el seminario menor con tres cargos directivos: padre espiritual, Manuel Tobar Marín; presidente de la primera sección, el licenciado Antonio Torrado Marín, y presidente de la segunda sección el diácono Anselmo Bracho Quijano.

29 BOAS. N. 140 (1888) 361-368; BOAS. N. 141 (1888) 402-408; BOAS. N. 142 (1888) 432-439.

30 Colección Legislativa de España 56, Madrid, 1852, 78-80. 
CURSOS, ASIGNATURAS Y TEXTOS EN HUMANIDADES

\begin{tabular}{|c|c|c|}
\hline CURSO & ASIGNATURA & TEXTO \\
\hline Primero & Sintaxis de ambas lenguas & Araujo \\
\hline " & Historia sagrada & Pintón \\
\hline$"$ & Geografía & Letronne y Verdejo \\
\hline Segundo & Prosodia y ortografía & Araujo \\
\hline$"$ & Historia profana & Castro \\
\hline " & Geografía & Letronne yVerdejo \\
\hline Tercero & Retórica y poética & Deloconia y Juvencio \\
\hline$"$ & Historia profana & Castro \\
\hline$"$ & Griego & Patavina o Petisco \\
\hline " & Geografía & Letronne yVerdejo \\
\hline Cuarto & Retórica y poética & Deloconia y Juvencio \\
\hline$"$ & Historia de España & Gómez o Cortada \\
\hline " & Griego & Patavina o Petisco \\
\hline " & Geografía & Letronne y Verdejo \\
\hline
\end{tabular}

Además de estos libros de texto indicados, para la traducción latina y castellana se seguía el primero y segundo de la colección de autores selectos para uso de las Escuelas Pías. También los libros de Officiis de San Ambrosio, el libro de Praescriptionibus de Tertuliano y las Poesías de Lactancio y Prudencio.

Las clases de latinidad y humanidades constaban de dos horas por la mañana y dos por la tarde, destinándose media hora diaria para historia sagrada, historia profana, historia de España y lengua griega.

\subsubsection{Filosofía}

La filosofía se cursaba en tres años con las asignaturas y textos que vemos reflejado en el cuadro adjunto.

CURSOS, ASIGNATURAS Y TEXTOS EN FILOSOFÍA

\begin{tabular}{|c|c|c|}
\hline CURSO & ASIGNATURA & TEXTO \\
\hline Primero & Lógica & Bonelli o Liberatore \\
\hline “ & Metafísica & Bonelli o Liberatore \\
\hline “ & Historia de la filosofía & Bonelli o Liberatore \\
\hline Segundo & Ética & Liberatore o Balmes \\
\hline “ & Matemáticas & Vallejo \\
\hline Tercero & Física experimental y nociones de química & Valledor y Chavarri \\
\hline " & Cálculo diferencial e integral & Vallejo \\
\hline
\end{tabular}


Las clases de filosofía durarán hora y media por la mañana y hora y media por la tarde, destinándose la primera media hora de la mañana para la historia de la filosofía y la primera media hora de la tarde para ejercicios de argumentación en forma silogística. En los cursos que solamente tienen dos asignaturas -segundo y tercero- dichos ejercicios se practicarán también en la media hora de la mañana. La cátedra del tercer curso de filosofía, que reúne las enseñanzas de principios de cálculos y de físico-matemáticas, destinará para el cálculo los tres primeros meses del curso y los seis restantes para físico-matemáticas.

\subsubsection{Teología}

El estudio de la sagrada teología se cursará en siete años con las siguientes asignaturas y textos:

CURSOS, ASIGNATURAS Y TEXTOS EN TEOLOGÍA

\begin{tabular}{|c|c|c|}
\hline CURSO & ASIGNATURA & TEXTO \\
\hline Primero & Fundamentos de religión & Perrone \\
\hline$"$ & Lugares teológicos & Perrone \\
\hline " & Elementos de lengua hebrea & Slaugther o Pacini \\
\hline Segundo & Instituciones teológico-dogmáticas & Perrone \\
\hline " & Historia y disciplina eclesiástica & Palma \\
\hline$"$ & Lengua hebrea & Slaugther o Pacini \\
\hline Tercero & Instituciones teológico-dogmáticas & Perrone \\
\hline “ & Historia y disciplina eclesiástica & Palma \\
\hline$"$ & Teología moral & Galán o Scavini \\
\hline Cuarto & Teología dogmática & Perrone \\
\hline " & Teología moral & Galán o Scavini \\
\hline$"$ & Historia y disciplina eclesiástica & Palma \\
\hline Quinto & Instituciones bíblicas & Jasenns \\
\hline \multirow[t]{2}{*}{ " } & Patrología & Annato o Tricalet \\
\hline & Oratoria sagrada & Fray Luis de Granada \\
\hline Sexto & Sagradas escrituras & Schaefer o Mellini \\
\hline$"$ & Patrología & Annato o Tricalet \\
\hline “ & Oratoria sagrada & Fray Luis de Granada \\
\hline Sexto & Sagradas escrituras & Schaefer o Mellini \\
\hline$"$ & Patrología & Annato o Tricalet \\
\hline “ & Oratoria sagrada & Fray Luis de Granada \\
\hline Séptimo & Disciplina del concilio de Trento & Gallemart y Villanuño \\
\hline
\end{tabular}


Con los cuatro cursos de teología podía obtenerse el grado de bachiller. Las clases de teología durarán hora y media por la mañana y hora y media por la tarde, destinándose media hora diaria para lengua hebrea, historia y disciplina eclesiástica y oratoria sagrada. Media hora de la tarde se dedicaba a los ejercicios de argumentación silogística. El título de más rango que se podía obtener en sagrada teología en el seminario de Sevilla antes de la erección de la universidad pontificia era el grado de bachiller.

\subsubsection{Derecho canónico}

El estudio del derecho canónico constaba de tres cursos, como podemos ver reflejados en el siguiente cuadro con sus respectivas asignaturas y textos.

\section{CURSOS, ASIGNATURAS Y TEXTOS EN DERECHO CANÓNICO}

\begin{tabular}{|l|l|l|}
\hline CURSO & ASIGNATURA & TEXTO \\
\hline Primero & Derecho público eclesiástico & Cardenal Soglia \\
\hline \multicolumn{1}{c|}{} & Instituciones canónicas & Devoti \\
\hline Segundo & Decretales & Maschat y Ubaldi \\
\hline Tercero & Disciplina del concilio de Trento & Gallemart y Villanuño \\
\hline
\end{tabular}

Las clases de cánones duraban hora y media por la mañana y hora y media por la tarde. Al concluir el segundo curso de cánones podía obtenerse el grado de licenciado y el doctorado al finalizar tercero. Los alumnos que hayan realizado la carrera completa de teología eran dispensados del tercer curso de cánones, en atención a que las materias que se enseñan en éste, las tienen ya estudiadas. Excluidos los cuatro seminarios centrales de España que podían conceder los grados de doctor, licenciado y bachiller, todos los demás solamente otorgaban el bachillerato en teología y cánones.

\subsubsection{La carrera abreviada}

La real cédula del 28 de septiembre de 1852 establece una carrera abreviada para los alumnos menos dotados intelectualmente o faltos de recursos económicos:

No siendo necesarios todos estos estudios a cuantos se dedican a la carrera eclesiástica, por haber en la Iglesia muchos ministerios que no requieren toda esta instrucción; ni hallándose todos en la disposición de hacerlos por falta de recursos o por no estar dotados de un entendimiento a propósito, los Ordinarios prescribirán a esta clase una carrera más abreviada ${ }^{31}$.

$31 \quad$ BOAS. N. 73 (1860) 184. 
La carrera abreviada constaba de seis cursos académicos: los tres primeros cursos de latinidad y humanidades, un curso de filosofía en el que se estudiaba lógica y metafísica y dos de teología en los que se cursaba la teología dogmática y la moral. Las clases de dogmática eran impartidas por un profesor especial para esta carrera y para la moral los alumnos se unían a los estudiantes de la carrera completa. Los libros de texto eran los mismos que los propuestos y utilizados en la carrera completa.

En la carrera corta predominan los alumnos externos. En el período comprendido entre el curso 1857-58 y el de 1878-79, año en que es suprimida, acabaron la carrera abreviada 47 alumnos internos y 243 externos $^{32}$. La carrera corta fue de nuevo instaurada en el curso 1897-98 con cuatro años de humanidades, uno de filosofía y tres en teología.

\subsection{Cambios en los planes de estudio}

El núcleo fundamental del plan de estudios de 1852 se respetará en las facultades de teología y cánones hasta la creación de la universidad pontificia de Sevilla en 1897. Los curso de filosofía y humanidades experimentarán cambios. A partir del curso 1878-79 se suprime un año de humanidades y al de tercero de filosofía se le da el nombre de preparatorio o ampliación.

El curso académico 1884-85 introduce unas pequeñas modificaciones. En el quinto de segunda enseñanza se suprime la asignatura de agricultura y se pone en su lugar francés. En el llamado curso de ampliación se sustituye por una nueva asignatura: cosmogonía, geología y prehistoria. El cambio afectará también a los estudios teológicos que incorporará en su plan de estudio el griego en primero de teología, desplazando el hebreo a segundo curso. Aparecen dos nuevas asignaturas: liturgia y teología pastoral que se impartirá en cuarto curso y ascética y mística en quinto ${ }^{33}$.

Los estatutos del 20 de mayo de 1888, promulgados por el arzobispo Ceferino González y Díaz Tuñón, afectarán a los planes de estudio de la segunda enseñanza y de la teología. El latín va a adquirir el rango de asignatura de capital importancia. Además de estar presente en el primer y segundo curso de humanidades y en el año de ampliación, según las disposiciones del citado prelado en 1884, a partir del curso 1888-89 se incluye en el tercer y cuarto curso de humanidades con clase diaria.

\section{PROGRAMAS DE LAS ASIGNATURAS}

El archivo del seminario, en depósito en el archivo diocesano desde 1996, conserva la mayor parte de los programas de las respectivas asignaturas desde el

32 M. MARTÍN RIEGO, La formación intelectual del clero. El seminario..., o. cit., 89-90; 101-103.

33 Ibid. 90-91. 
curso 1952-53, hasta la creación de la universidad pontificia en $1897^{34}$.Veamos el contenido de algunos de estos programas.

\subsection{Programas de latinidad y humanidades}

El programa de la asignatura de historia sagrada consta de 100 lecciones: 2 sobre fuentes y metodología, 60 sobre el antiguo testamento (desde la creación hasta el empadronamiento de Augusto), 27 sobre la figura de Cristo (desde el nacimiento a la resurrección) y 11 sobre el cristianismo apostólico ${ }^{35}$.

El programa de latín y castellano del primer curso de humanidades figura con 107 lecciones: 100 de gramática latina castellana y 7 de sintaxis latina. Estas lecciones iban acompañadas de ejercicios de lectura, análisis lexicológico y traducciones de trozos sencillos de historia sagrada y griega de la colección de Fernández de Velasco ${ }^{36}$. El de segundo curso está dedicado a la sintaxis con 95 lecciones: 60 de sintaxis latina y 35 de castellana ${ }^{37}$.

El estudio de la geografía en el primer año de humanidades está dedicado a la astronomía y a la cartografía con un total de 22 lecciones $^{38}$. La geografía física, política y descriptiva era materia de estudio del tercer y cuarto año de humanidades y su programa aparece con 50 lecciones: 17 de geografía física y 23 de descriptiva ${ }^{39}$.

El de historia universal, disciplina del segundo y tercer curso de humanidades, consta de 66 lecciones: una sobre fuentes y ciencias auxiliares, 22 de historia antigua, 23 de medieval, 18 de moderna y 2 de contemporánea (la Revolución Francesa y Napoleón). Cada época histórica lleva una pequeña introducción ${ }^{40}$.

El programa de historia de España aparece con 52 temas: uno de introducción general, 4 de historia antigua, 22 de medieval y 14 de moderna, finalizando con el reinado de Fernando VII ${ }^{41}$.

El estudio de la retórica consta de 31 lecciones sobre el lenguaje, las figuras, las reglas de estilo, la composición literaria, el sermón y las narraciones

34 AGSS. Leg. 233. Programas de las asignaturas. Hemos contabilizado y manejado más de un centenar de programas de la mayor parte de las materias.

35 AGSS. Leg. 233. Programa de historia sagrada del profesor Antonio Pohl Argobejo. Curso 1952-53.

36 AGSS. Leg. 233. Programa de latín y castellano de primero de humanidades del profesor Francisco del Castillo. Curso 1866-67.

37 AGSS. Leg. 333. Se trata del mismo programa del Instituto Provincial de Sevilla.

38 AGSS. Leg. 233. Programa de geografía del primer curso de humanidades del profesor Joaquín García García. Curso 1863-64.

39 AGSS. Leg. 233. Programa de geografía política y descriptiva de tercero y cuatro de humanidades del profesor Antonio Fernández Cabrera. Curso 1863-64.

40 AGSS. Leg. 233. Programa de historia universal de segundo y tercero de humanidades. Es el mismo programa del Instituto Provincial de Sevilla.

41 AGSS. Leg. 233. Programa de historia de España. Curso 1853-54. 
históricas $^{42}$. La poética aparece con 21 lecciones: lenguaje poético, oda, poemas disdascálicos y descriptivos, sátira, epigrama, soneto, letrilla, drama, tragedia, comedia, epopeya, égloga y fábula ${ }^{43}$.

Por último, el programa de griego, materia que se estudiaba en tercer y cuarto de humanidades, figura con 52 lecciones de gramática para el primer curso de griego y 50 de sintaxis para el segundo ${ }^{44}$.

\subsection{Programas de filosofía}

Las matemáticas eran estudiadas en los cursos de filosofía: los elementos de matemáticas en segundo y el cálculo diferencial e integral en tercero. El programa del primer año de matemáticas aparece con 82 lecciones: 37 de aritmética, 9 de geometría y 36 de trigonometría. Se incluyen los problemas de incógnitas de primer y segundo grado ${ }^{45}$.

La física experimental y las nociones de química, materia estudiada en el tercer curso de filosofía, figura en el respetivo programa con 56 lecciones de física y 21 de química ${ }^{46}$.

El programa de lógica consta de 29 lecciones, el de metafísica de 50, el de historia de la filosofía 11 y con 52 el de ética y derecho natural ${ }^{47}$. Estas materias se cursaban en primero y segundo de filosofía.

\subsection{Programas de teología}

El programa de lugares teológicos, materia de primer curso de teología, figura con 71 lecciones: 37 dedicadas a la religión, milagros y profecías y a la Iglesia con sus notas, 6 al romano pontífice, 4 a los concilios, 13 a las sagradas escrituras y 8 a la tradición y a los santos padres ${ }^{48}$. La teología dogmática se cursaba en segundo, tercero y cuarto de teología. El de instituciones teológicodogmáticas del segundo consta de 112 lecciones: 29 sobre Dios y sus atributos, 20 sobre Dios Trino, 29 sobre el Dios Encarnado, 28 sobre la gracia y 6 sobre el culto a los santos ${ }^{49}$. Las instituciones teológico-dogmáticas concluían en el cuarto de teología. Estaba dedicado a los sacramentos y el programa aparece con 84 temas: 14 para los sacramentos in genere y 70 para los in specie. De estos

42 AGSS. Leg. 233. Programa de retórica. Curso 1857-58.

43 AGSS. Leg. 233. Programa de poética. Curso 1857-58.

44 AGSS. Leg. 233. Programa de griego. Curso 1866-67.

45 AGSS. Leg. 233. Programa de matemáticas del profesor catedrático Francisco de Paula García Portillo. Curso 1857-58.

46 AGSS. Leg. 233. Programa de física y química. Curso 1861-62.

47 AGSS. Leg. 233. Programa de lógica, metafísica, historia de la filosofía, ética y derecho natural del profesor Francisco del Castillo. Curso 1863-64.

48 AGSS. Leg. 233. Programa de sagrada teología. Curso 1867-68.

49 AGSS. Leg. 233. Programa de segundo curso de sagrada teología. Curso 1859-60. 
70, 11 para el bautismo, 5 a la confirmación, 24 a la eucaristía, 18 a la penitencia e indulgencias, 2 sobre la extremaunción y 10 sobre el sacramento del orden ${ }^{50}$.

La teología moral se cursaba en el tercer y cuarto año de la carrera teológica. El programa de tercero estaba centrado en la moral y las virtudes y constaba de 70 temas: 2 sobre el objeto y fin de la moral, 13 sobre los actos humanos, 6 sobre la conciencia, 20 sobre las leyes, 15 sobre el pecado y 14 sobre las virtudes ${ }^{51}$. La teología moral de cuarto estudiaba los sacramentos y su programa tenía 40 lecciones: 11 sobre los mismos in genere y 39 in specie ${ }^{52}$. Los alumnos de la carrera abreviada tenían los mismos programas de teología moral, ya que cursaban dicha disciplina con los de la carrera completa.

Las sagradas escrituras es la asignatura fuerte de quinto y sexto de teología. El primer año de hermenéutica estudiaba las sagradas escrituras en general, la inspiración, la doctrina de los concilios, los sentidos de las sagradas escrituras y la historia del pueblo de Israel con un total de 100 lecciones $^{53}$. El segundo curso de hermenéutica se centraba en el estudio concreto de cada uno de los libros de las sagradas escrituras con 75 temas: 46 para el antiguo testamento y 29 para el nuevo ${ }^{54}$.

La historia de la Iglesia, junto con la disciplina eclesiástica, se cursaba en tres años: segundo, tercero y cuarto de teología. El primer año de historia eclesiástica constaba de 24 temas de disciplina en general y 66 de historia antigua, empezando por la predicación de los apóstoles y concluyendo con el imperio de Carlomagno ${ }^{55}$. El segundo año estaba dedicado a la historia medieval, iniciándose con el pontificado de Gregorio VII y finalizando con León X con un total de 91 temas. El tercer curso arrancaba con Lutero y concluía con el problema del jansenismo y del quietismo con un total de 59 lecciones. El programa de cada curso de historia eclesiástica se iniciaba con unas lecciones introductorias de metodología, fuentes, ciencias auxiliares, historiadores eclesiásticos y división de las edades de la Iglesia. La tendencia de los programas de historia eclesiástica es de claro matiz apologético y antiprotestante ${ }^{56}$.

El estudio de la patrología y oratoria sagrada se realizaba en el quinto y sexto de la carrera teológica. El primer curso de patrología analizaba los padres

50 AGSS. Leg. 233. Programa de instituciones teológico-dogmáticas. Curso 1855-56.

51 AGSS. Leg. 233. Programma theologiae moralis iuxta Gury compendium a doctore Vicentio Iborra García. Curso 1876-77.

52 AGSS. Leg. 233. Programa de teología moral. Curso 1866-67.

53 AGSS. Leg. 233. Programa de hermenéutica sagrada del doctor Ramón Mauri Puig. Curso 1863-64.

54 AGSS. Leg. 233. Programma sacrae scripturae. Curso 1872-73.

55 AGSS. Leg. Programas de historia y disciplina eclesiástica por el doctor José Torres Padilla. Cursos 1857-58; 1858-59 y 1859-60. Doctor en teología, canónigo y confesor de Santa Ángela de la Cruz. Consultor de concilio Vaticano I en la comisión de disciplina eclesiástica. Falleció en Sevilla en 1878.

56 Esta tendencia se mantiene en la casi totalidad de los manuales de historia de la Iglesia antes del concilio Vaticano II. 
apostólicos y los no apostólicos o de la segunda generación con un total de 54 lecciones. La oratoria sagrada figura con 25 temas. En el curso siguiente se daba el mismo programa ${ }^{57}$.

El séptimo curso de teología tenía una sola asignatura: Disciplina del concilio de Trento y particular de España conforme a sus concilios y concordatos. El programa constaba de 181 lecciones: 13 sobre el cristianismo en España hasta el Tridentino, 5 sobre el concilio de Trento, 3 sobre la disciplina eclesiástica en general, 5 sobre los concilios ecuménicos, nacionales, provinciales y diocesanos, uno sobre los concordatos españoles, 2 sobre las colecciones canónicas en España, 41 sobre la jerarquía eclesiástica (romano pontífice, cardenales, arzobispos y obispos), 7 sobre vicarios generales, órdenes militares, comisario general de la cruzada y vicariato general de los ejércitos de España, 8 sobre los cabildos catedralicios, 3 sobre las parroquias y sus titulares, 16 sobre las órdenes sagradas (sus impedimentos, obligaciones de los clérigos, títulos de ordenación, inmunidad eclesiástica y hábitos), 6 sobre el monacato y los religiosos, 11 sobre la disciplina sacramental, 18 sobre el matrimonio (impedimentos y nulidad), 30 sobre las prerrogativas de la Iglesia, beneficios, diezmos y bienes, 3 sobre la enajenación de los bienes eclesiásticos y 9 sobre los tribunales de la Iglesia ${ }^{58}$.

\subsection{Programas de derecho canónico}

Los estudios de cánones se realizaban en tres años. El programa de la asignatura de derecho público eclesiástico e instituciones canónicas, explicadas en el primer curso, constaba de 109 lecciones: 10 de introducción al estudio del derecho canónico, 17 a la historia del mismo, 56 dedicadas a las personas y 26 a las $\operatorname{cosas}^{59}$. Las Decretales eran cursadas en el segundo de cánones con 81 lecciones: 33 sobre las cosas, 23 sobre el derecho criminal eclesiástico (delitos y penas) y 25 sobre la potestad judicial de la Iglesia y el fuero eclesiástico ${ }^{60}$. La asignatura del tercer curso, Disciplina del concilio de Trento y particular de España, conforme a sus concilios y concordatos, se cursaba en el séptimo de la carrera teológica. Como es obvio, con el mismo programa.

AGSS. Leg. 233. Programa de patrología y elocuencia sagrada por el doctor José Torres Padilla. Curso 1859-60.

58 AGSS. Leg. 233. Programa de disciplina del concilio de Trento y particular de España por el doctor Antonio López Porras. Curso 1863-64.

59 AGSS. Leg. 233. Programa de instituciones canónicas del primer año de derecho canónico por el doctor Ramón de Beas Dutari. Curso 1861-62.

60 AGSS. Leg. 233. Programa de segundo año de sagrados cánones por el doctor Ramón de Beas Dutari. Curso 1862-63. 


\section{LOS ALUMNOS DEL SEMINARIO (1878-1890)}

\subsection{Latinidad y humanidades}

Los alumnos matriculados en latinidad y humanidades desde 1878-79, curso académico en el que comenzó sus estudios Muñoz y Pabón, hasta el curso 1881-82 en el que los finalizó quedan reflejados en el siguiente cuadro.

\section{ALUMNOS DE LATINIDAD Y HUMANIDADES (1878-1882)}

\begin{tabular}{|l|c|c|c|c|c|c|c|c|c|c|}
\hline CURSO & \multicolumn{2}{|c|}{ PRIMERO } & \multicolumn{2}{c|}{ SEGUNDO } & \multicolumn{2}{c|}{ TERCERO } & \multicolumn{2}{c|}{ CUARTO } & \multicolumn{2}{c|}{ TOTAL } \\
\hline & In. & Ex. & In. & Ex. & In. & Ex. & In. & Ex. & In. & Ex. \\
\hline $1878-79$ & 14 & 50 & 11 & 31 & 14 & 18 & 4 & 16 & 43 & 115 \\
\hline $1879-80$ & 13 & 69 & 14 & 37 & 12 & 34 & 10 & 18 & 49 & 158 \\
\hline $1880-81$ & 6 & 28 & 10 & 33 & 14 & 36 & 14 & 31 & 44 & 128 \\
\hline $1881-82$ & 33 & - & 6 & 33 & 11 & 31 & - & - & 50 & 64 \\
\hline
\end{tabular}

Como podemos observar, los alumnos externos superan a los internos. En el curso 1982-83 se inicia un incremento de los seminaristas internos que se mantendrá hasta el curso 1896-97, volviendo de nuevo a superar los externos a los internos desde el curso 1897-98 al 1900-01. El alza de internos en el periodo 188792 está en estrecha relación con la apertura del seminario menor en el antiguo convento de la Trinidad. Dos causas fundamentales son las que originaron tal cantidad de alumnos externos en el seminario de Sevilla: el reducido y deficiente edificio de Maese Rodrigo y el bajo nivel económico del establecimiento y de los seminaristas. La ubicación del seminario en el Palacio de San Telmo hará que solamente entren como externos alrededor de una docena ${ }^{61}$.

\subsection{Teología}

Los alumnos matriculados en teología desde el curso 1884-85 hasta 188990 quedan reflejados en el cuadro adjunto:

\section{ALUMNOS MATRICULADOS EN TEOLOGÍA (1884-1890)}

\begin{tabular}{|l|c|c|c|c|c|c|c|c|c|c|c|c|c|c|}
\hline CURSO & \multicolumn{2}{|c|}{$\mathbf{1}^{\mathbf{0}}$} & \multicolumn{2}{|c|}{$\mathbf{2}^{\mathbf{0}}$} & \multicolumn{2}{c|}{$\mathbf{3}^{\mathbf{0}}$} & \multicolumn{2}{c|}{$\mathbf{4}^{\mathbf{0}}$} & \multicolumn{2}{c|}{$\mathbf{5}^{\mathbf{0}}$} & \multicolumn{2}{c|}{$\mathbf{6}^{\mathbf{0}}$} & \multicolumn{2}{c|}{ TOTAL } \\
\hline & In. & Ex. & In. & Ex. & In. & Ex. & In. & Ex. & In. & Ex. & In. & Ex. & In. & Ex. \\
\hline $1884-85$ & 33 & 15 & 22 & 15 & 6 & 9 & 12 & 1 & 7 & 3 & 2 & 2 & 82 & 45 \\
\hline $1885-86$ & 28 & 14 & 31 & 12 & 30 & 11 & 6 & 6 & 3 & 4 & 3 & 2 & 101 & 49 \\
\hline $1886-87$ & 13 & 6 & 25 & 13 & 38 & 12 & 21 & 10 & 5 & 3 & 3 & 3 & 105 & 47 \\
\hline $1887-88$ & 31 & 6 & 11 & 5 & 33 & 3 & 38 & 2 & 10 & 3 & 2 & 4 & 125 & 23 \\
\hline $1888-89$ & 26 & 8 & 32 & 6 & 13 & 3 & 30 & 4 & 24 & 2 & 6 & 3 & 121 & 24 \\
\hline $1889-90$ & 24 & 6 & 28 & 9 & 36 & 5 & 17 & 2 & 22 & 10 & 18 & 7 & 145 & 39 \\
\hline
\end{tabular}

${ }^{61}$ M. MARTIN RIEGO, La formación intelectual del clero. El seminario... o. cit. 134-138. 
A partir del curso 1983-84 se observa un elevado incremento en el número de matriculados en teología. No obstante, la diferencia entre los alumnos que comienzan los estudios teológicos y los que los finalizan era abismal. Era frecuente la retirada en el quinto año de humanidades. Como vemos los alumnos matriculados como internos son más en número que los externos. Era más frecuente que los alumnos de humanidades fueran externos e internos los de teología. Los de cánones suelen ser externos ${ }^{62}$. Tal es el caso de Muñoz y Pabón que durante sus años de humanidades fue externo y durante la teología interno para volver a ser externo en los estudios de cánones.

\section{LA FIGURA DE JUAN FRANCISCO MUÑOZ Y PABÓN}

\subsection{Nacimiento y familia}

Nació en Hinojos el 16 de junio de 1866 a las tres de la mañana. Fue bautizado en la parroquia de Santiago el Mayor por Serafín Berrocal, cura ecónomo. Hijo legítimo de Antonio Muñoz, sochantre de la parroquia, y María Josefa Pabón. Fueron sus abuelos paternos Juan Muñoz, propietario, y María Florencia García, naturales y vecinos de Hinojos, y los maternos Juan Pabón -difunto- y Dorotea Illanes, también naturales de Hinojos. Los padrinos: Manuel Pichardo y María de los Santos Muñoz, su mujer, naturales y vecinos de dicha villa. Actuaron como testigos Francisco León, sacristán menor, y Manuel León, acólito. La fe de bautismo la extendió Juan José Japón Haro, cura ecónomo ${ }^{63}$.

La familia de Juan Francisco Muñoz y Pabón vivía en la calle del Cura, número siete.

\subsection{Entrada en el seminario}

Con fecha 22 de agosto de 1878 solicitó al arzobispo que fuera admitido con alumno externo en el seminario conciliar de Sevilla:

... Que para mejor servicio a Dios nuestro Señor desea seguir la carrera, para lo cual no tienen sus padres los recursos que son necesarios para costearlo en esta ciudad capital como no sea pagando una subvención muy reducida.

Pide se le admita como alumno externo de la Obra Pía de estudiantes pobres y matricularse en primer año de latinidad ${ }^{64}$.

Muñoz y Pabón fue alumno de la segunda sección (pobres) hasta su ordenación sacerdotal en 1890.

Ibid. 94-101.

AGSS. Leg. 65. En este expediente encontramos su fe de bautismo.

64 AGSS. Leg. 65. En este expediente encontramos las calificaciones anuales y todo lo referente a su vida académica. 


\subsection{Expediente académico}

\subsubsection{Humanidades}

Antes de ingresar en el seminario realizó el examen de ingreso, obteniendo la máxima calificación, Meritissimus, en todas las materias: lectura, escritura, doctrina cristiana, principio de lengua castellana y principio de lengua latina. En la solicitud para la matrícula de primero de segunda enseñanza figura como alumno externo, viviendo en la calle López Pintado de Sevilla, siendo su tutor su tío Juan Francisco. El curso siguiente residió en el número tres de la calle Santiago.

Los cinco años de segunda enseñanza y el de ampliación los realizó entre el curso el 1878-79 y 1883-84. Siempre como alumno externo de la segunda sección. Obtuvo las máximas calificaciones, según podemos observar en el siguiente cuadro.

CALIFICACIONES DE SEGUNDA ENSEÑANZA

\begin{tabular}{|c|c|c|}
\hline CURSO & ASIGNATURA & CALIFICACIÓN \\
\hline \multirow[t]{3}{*}{$1878-79$} & Latín & Meritissimus \\
\hline & Castellano & " \\
\hline & Geografía & “ \\
\hline \multirow[t]{3}{*}{$1879-80$} & Latín & “ \\
\hline & Castellano & " \\
\hline & Historia universal & “ \\
\hline \multirow[t]{2}{*}{$1880-81$} & Retórica & “ \\
\hline & Matemáticas & “ \\
\hline \multirow[t]{2}{*}{$1881-82$} & Psicología, lógica y ética & “ \\
\hline & Geometría & “ \\
\hline \multirow[t]{3}{*}{$1882-83$} & Física y química & " \\
\hline & Historia natural con fisiología e higiene & “ \\
\hline & Agricultura & \\
\hline \multirow[t]{3}{*}{$1883-84$} & Metafísica & " \\
\hline & Perfección latina & " \\
\hline & Griego & “ \\
\hline
\end{tabular}

\subsubsection{Teología}

Entre el curso académico 1884-85 y el 1890-91 estudió los siete años de teología con las calificaciones que refleja el cuadro adjunto. 


\section{CALIFICACIONES DE LOS ESTUDIOS TEOLÓGICOS}

\begin{tabular}{|c|c|c|}
\hline CURSO & ASIGNATURA & CALIFICACIÓN \\
\hline \multirow[t]{3}{*}{$1884-85$} & Fundamentos de religión & Meritissimus \\
\hline & Lugares teológicos & “ \\
\hline & Griego & " \\
\hline \multirow[t]{3}{*}{$1885-86$} & Dogma (primero) & Benemeritus \\
\hline & Historia eclesiástica (primero) & " \\
\hline & Hebreo & Meritissimus \\
\hline \multirow[t]{3}{*}{$1886-87$} & Dogma (segundo) & " \\
\hline & Historia eclesiástica (segundo) & " \\
\hline & Moral (primero) & “ \\
\hline \multirow[t]{4}{*}{$1887-88$} & Dogma (tercero) & " \\
\hline & Moral (segundo) & “ \\
\hline & Teología pastoral & " \\
\hline & Arqueología cristiana & “ \\
\hline \multirow[t]{4}{*}{$1888-89$} & Sagradas escrituras (primero) & “ \\
\hline & Patrología (primero) & “ \\
\hline & Oratoria sagrada (primero) & “ \\
\hline & Liturgia y cómputo eclesiástico & “ \\
\hline \multirow[t]{4}{*}{$1889-90$} & Sagradas escrituras (segundo) & " \\
\hline & Patrología (segundo) & $"$ \\
\hline & Oratoria sagrada (segundo) & “ \\
\hline & Ascética y mística & “ \\
\hline $1890-91$ & Disciplina general del concilio de Trento & “ \\
\hline
\end{tabular}

\subsubsection{Cánones}

\section{CALIFICACIONES EN CÁNONES}

\begin{tabular}{|l|l|l|}
\hline \multicolumn{1}{|c|}{ CURSO } & ASIGNATURA & CALIFICACIÓN \\
\hline $1891-92$ & Instituciones canónicas & Meritissimus \\
\hline $1892-93$ & Decretales & Meritissimus \\
\hline
\end{tabular}

Entre el curso 1898-99 y el siguiente, siendo ya catedrático de varias asignaturas de humanidades, se matriculó en el bienio de derecho canónico, obteniendo la calificación de Meritissimus en las asignaturas de instituciones de derecho canónico público y privado con nociones de derecho civil y de gentes y en la de decretales con las principales cuestiones de derecho romano y patrio ${ }^{65}$.

65 AGSS. Leg. 210 y 211. Actas de exámenes y cuadernos de pruebas de curso. 
Con fecha 21 y 22 de septiembre de 1891 realizó el examen de bachillerato en teología, siendo jueces los doctores Silvestre Pérez Godoy, Juan Crisóstomo Vacas y Juan Bautista Serra. Entre las proposiciones sacadas a suerte -1, 35 y 60- eligió esta última. Obtuvo la calificación de aprobado nemine discrepante. Fue dispensado de las dos terceras partes de los derechos de exámenes ${ }^{66}$. Al no poder el seminario de Sevilla conceder el grado de licenciado y doctor, se matriculó en el seminario central de Granada, obteniendo ambos grados con la calificación de nemine discrepante ${ }^{67}$.

\subsection{Muñoz y Pabón como profesor}

Antes de finalizar los estudios de cánones es nombrado profesor del seminario. En el curso 1887-88, siendo alumno de cuarto de teología, ya figura como profesor interino de retórica y poética. En el curso 1890-91, estudiando séptimo de teología, es designado por el arzobispo profesor de latín de tercero y de retórica y poética. De 1893 a 1897 es catedrático de retórica y de latín de cuarto.

Recién creada la universidad pontificia, pasa a la facultad de teología como profesor interino de teología desde el 1 de septiembre de 1897. Y desde 1903 a 1920, fecha de su fallecimiento, era catedrático de sagradas escrituras ${ }^{68}$, parte teórica, según podemos ver en el libro de registro de profesore ${ }^{69}$ y en el libro de actas del colegio de doctores ${ }^{70}$.

Desde el 21 de diciembre de 1903 hasta su muerte figura como miembro del colegio de doctores de la facultad de teología ${ }^{71}$.

\subsection{Lección inaugural del curso 1897-98}

El curso académico 1897-98, tras tres días de ejercicios espirituales como preparación, se inauguró el 4 de octubre, acto que tuvo una excepcional importancia por haberse abierto los cursos académicos de las tres facultades de teología, derecho canónico y filosofía, recién erigidas por la autoridad apostólica. Tras la profesión de fe por parte de los catedráticos, se procedió a entregar a los alumnos premiados los diplomas justificativos de sus merecimientos. Ocupó la cátedra el doctor Juan Manuel Muñoz y Pabón, profesor de literatura, de cuarto año de humanidades, quien leyó "un hermoso discurso sobre Jesucristo considerado como belleza y belleza y belleza suprema y belleza fecunda"72.

\footnotetext{
66 AGSS. Libro 65.Libro primero de asientos de grados de bachiller en teología y derecho canónico de 1855 a 1897.

67 AGAS. Fondo Catedral. Sección: Fondo Histórico General, n. 213 (2).

68 AGSS. Leg. 8. Exemplum relationis ad Sancram Congregationem Studiorum.

69 AGSS. Leg. 8.

70 AGSS. Libro 10. Libro de actas del colegio de doctores.

71 AGSS. Libro 70. Registro de turnos para asistencia y argumentos.

72 BOAS. N. 374 (1897) 244.
} 
Después de un largo y poético saludo y desiderata, nos presente el esquema de su discurso inaugural: "Vamos, pues, a estudiar la belleza en sus relaciones con Jesucristo; o mejor, a hablar un rato sobre Jesucristo, por lo que hay en él de belleza. No será, sin embargo, sin antes asentar esta sencilla proposición: Jesucristo es belleza; y belleza suprema; y belleza fecunda"73. Comienza hablando, de una forma general, sobre la belleza de Dios.

La belleza de Jesucristo la defiende en varios apartados. Lo estudia en su supuesto teológico los tres elementos estéticos: unidad, variedad y armonía. Jesucristo es unidad porque es una sola Persona y con efecto.Y termina confesando la sublime cláusula del símbolo apostólico:"Credo in unum... Jesum Christum"74. Pero, si bien es uno, como uno es Dios, es a la vez variedad prodigiosamente varia. Cristo, según el sínodo de Calcedonia, tiene dos naturalezas, divina y humana. Pero, Jesucristo también es armonía. La armonía de la creación se vio truncada por el hombre. Subraya la belleza de Cristo en su santidad: "Cristo es el prototipo de la santidad; y el modelo divino por que se hacen los santos"75. En definitiva, Dios es la santidad, Jesucristo es el santo y los santos su hechura: Tu solus sanctus, Jesu Christe.

Y termina su discurso con un canto a la belleza fecunda de Cristo: "La belleza de Cristo es fecunda, porque crea un arte nuevo; porque el arte que crea no se parece a ninguno, más que a si mismo; y porque, puesto a embellecerlo todo, ha llegado a embellecerlo esencialmente deforme ${ }^{\prime \prime 76}$. La influencia de Jesucristo ha creado un arte nuevo. Nadie que haya manejado la historia del arte lo pone en duda. El doctor Muñoz y Pabón hace un recorrido por la historia de la pintura y escultura, subrayando la escuela sevillana:

El arte de Cristianismo es el Thabor en donde lo deforme se transfigura, flamea $y$ se diviniza. Ni es menester salir de Sevilla para probar hartamente nuestra aseveración. Nuestra escuela pictórica y estatuaria hablan con más elocuencia que todos los libros ${ }^{77}$.

Por último, menciona importantes artistas sevillanos o que dejaron su impronta en Sevilla. Ente los pintores enumera los siguientes: Alejo Fernández, Luis de Vargas, Zurbarán, Roelas, Herrera el Viejo, Herrera el Mozo, Bartolomé Murillo, Diego Velázquez, Valdés Leal. Y entre los escultores: Jerónimo Hernández, Gijón, Hita, Roldán, la Roldana, Martínez Montañés, Juan de Mesa. Y entre las esculturas cita la de Jesús de Pasión, la del Gran Poder y la del Cristo de la Expiración.

Y finaliza su discurso con las siguientes palabras: "; Salve, pues, inefable belleza que te llamas el Cristo del Señor, belleza suprema en lo físico, en lo

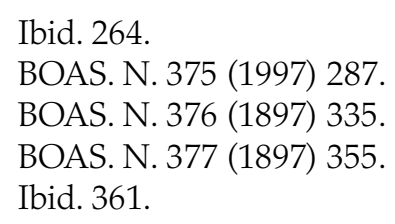


intelectual y moral, belleza fecunda, hasta crear un arte nuevo, semejante solo a sí mismo, y embellecedor de cuanto toca. En fin, encarnada Idea estética del Dios belleza absoluta!"78.

\subsection{Carrera eclesiástica}

Como ya hemos indicado, Juan Francisco Muñoz y Pabón nació en Hinojos en 1866, "de una modesta familia de arraigadas creencias cristianas"79. Según el boletín oficial del arzobispado, "el extraordinario despejo y la piedad que mostró desde pequeño, brillaron en él durante la carrera sacerdotal, que cursó con extraordinario aprovechamiento en el Seminario de Sevilla" ${ }^{10}$. Destacó entre sus compañeros por su "aplicación, su inteligencia, su ingenio, su alegría y sus travesuras inocentes que en nada menguaban sus relevantes virtudes" ${ }^{\prime 81}$.

Con fecha 21 y 22 de diciembre de 1888 fue ordenado de tonsura y de los cuatro grados ${ }^{82}$, en las témporas de Adviento, y en las mismas témporas de 1889 de diácono ${ }^{83}$. De presbítero fue ordenado el 31 de mayo de $1890^{84}$, en las témporas de Pentecostés, con dispensa de la edad canónica ${ }^{85}$. En 1886 fue nombrado prefecto de disciplina interna del seminario y en 1890 presidente de disciplina interna.

Según los datos conservados, el 9 de febrero de 1894 fue nombrado cura ecónomo de la parroquia de Santiago el Mayor de Sevilla y en 1903 ecónomo del Sagrario $^{86}$. Tras el fallecimiento del doctor José López García, canónigo lectoral, el 14 de agosto de 1903, se hizo público el edicto de convocatoria de las oposiciones. Entre los seis opositores figura el doctor Muñoz y Pabón, defendiendo el 21 de octubre durante una hora el capítulo 44 del profeta Isaías la siguiente conclusión:

Messias, in persona Cyri praefiguratus, in aeternitate genitus et tempore natus apparet mundi redemptor, ecclesiae fundator et rex saecolurum ${ }^{87}$.

Tras su exposición, fue argumentado durante media hora por los doctores José Moreno Maldonado y Cristino Marrodo Rodríguez, canónigos. Obtuvo 14 votos frente a los 5 del siguiente. El arzobispo Spínola y Maestre eligió a Muñoz

Ibid. 363.

BOAS. N. 949 (1920) 547-548.

Ibid. 547.

Ibid. 548.

BOAS. N. 143 (1888), 452.

BOAS. N. 167 (1889) 457.

BOAS. N. 180 (1890) 477.

AGAS. Fondo Catedral. Sección Fondo Histórico General, n. 213 (2).

Ibidem.

Ibidem. 
y Pabón ${ }^{88}$. Tomó posesión el 5 de noviembre de 1903 de la prebenda 14 como lectoral, según podemos leer en el libro de entrada de prebendados:

El 31 de Octubre de 1903 fue nombrado canónigo lectoral de esta Santa Iglesia el Sr. Doctor don Juan Francisco Muñoz y Pabón, cura ecónomo que era de la Parroquia del Sagrario de esta ciudad. Fue nombrado por el Excmo. y Rdmo. Sr. Arzobispo y el Cabildo de Señores Canónigos in sacris, previa oposición según las dispo-/ siciones canónicas y tomó posesión de dicha canongía Lectoral el 5 de Noviembre de 1903.

El día 31 de Diciembre de 1920 quedó vacante esta canongía lectoral por defunción del anterior poseedor ${ }^{89}$.

Falleció en Sevilla el 30 de diciembre de 1920. Fue enterrado en el panteón capitular del cementerio de San Fernando de Sevilla. Fue un elocuente predicador. Perteneció a la Real Academia Sevillana de Buenas Letras de Sevilla como académico de número. Examinador sinodal del arzobispado de Sevilla y de la diócesis de Málaga. Secretario del colegio de examinadores. Tenía licencias ministeriales absolutas en el arzobispado de Sevilla y en varias diócesis.

88 Según el informe de la relación de méritos firmado por el arzobispo, "era un sacerdote de buena vida y costumbres, asiduo en la predicación de la divina palabra, sin que haya incurrido, que sepamos, en censura ni pena alguna canónica; hallándose por el contario en pleno uso de su sagrado ministerio, siendo por tanto acreedor a cualquier ascenso o recompensa".

89 AGAS. Fondo Capitular. Sección. Secretaría. Serie. Personal. Libro de Entrada de Prebendados. Sign. 11130. Con fecha 31 de octubre de 1921 tomó posesión como canónigo lectoral el doctor Balbino Santos Olivera, profesor en la facultad de teología de la universidad pontificia de Sevilla. 


\section{ANEXO PRIMERO}

\section{CLAUSTRO DE PROFESORAES DEL SEMINARIO (1878-1920)}

El seminario conciliar de Sevilla tuvo un excelente claustro de profesores en la época en la que estudió Juan Francisco Muñoz y Pabón, como puede verse en el alto número de doctores. En el siguiente anexo ofrecemos la relación de los profesores que impartieron clases a Muñoz y Pabón y los que coincidieron con él en su etapa de profesor ${ }^{90}$.

\begin{tabular}{|c|c|}
\hline PROFESOR & MATERIA \\
\hline \multirow{5}{*}{ Dr. Abín Pinedo, Modesto } & Retórica y poética (1878-1881) \\
\hline & Historia de España (1878-1881) \\
\hline & Perfección latina (1878-1881) \\
\hline & Fundamentos de religión (1881-1890) \\
\hline & Teología general (1897-1923) \\
\hline \multirow{3}{*}{ Dr. Alejos Benavente, Manuel } & Auxiliar de teología (1910-1911) \\
\hline & Derecho público eclesiástico (1911-1912) \\
\hline & Derecho canónico privado (1912-1915) \\
\hline \multirow{4}{*}{ Dr. Álvarez Troya, Jerónimo } & Matemáticas (1876-1881) \\
\hline & Física y química (1881-1887) \\
\hline & Sagradas escrituras (1881-1890) \\
\hline & Instituciones canónicas (1897-1898) \\
\hline Dr. Álvarez Troya, Juan & Instituciones canónicas (1897-1898) \\
\hline \multirow{2}{*}{ Dr. Andújar Carrasco, Sebastián } & Matemáticas (1897-1901) \\
\hline & Historia natural (1902-1904) \\
\hline \multirow{6}{*}{ Lc. Aparicio Marín, Victoriano } & Latín y castellano de Segundo (1887-1888) \\
\hline & Latín de tercero (1888-1889) \\
\hline & Retórica y poética (1888-1889) \\
\hline & Historia universal (1888-1889) \\
\hline & Teología pastoral (1889-1890) \\
\hline & Ascética y mística (1889-1890) \\
\hline \multirow{2}{*}{ Dr. Arbolí Faraudo, Servando } & Patrología (1876-1887) \\
\hline & Elocuencia sagrada (1876-1887) \\
\hline Dr. Arellano Santos, Antonio & Auxiliar de filosofía (1897-1898) \\
\hline
\end{tabular}

90 M. MARTÍN RIEGO, La formación intelectual del clero..., o. cit., 119-124; 186-190. 


\begin{tabular}{|c|c|}
\hline PROFESOR & MATERIA \\
\hline \multirow{5}{*}{ Dr. Armario Rosado, Jerónimo } & Astronomía (1897-1922) \\
\hline & Dialéctica práctica (1897-1898) \\
\hline & Auxiliar de teología (1898-1901) \\
\hline & Lengua hebrea (1901-1904) \\
\hline & Teología dogmática (1901-1922) \\
\hline \multirow{7}{*}{ Dr. Baena Marín, Manuel } & Latín de cuarto (1887-1893) \\
\hline & Ejercicios de latín (1887-1893) \\
\hline & Perfección latina (1888-1897) \\
\hline & Psicología y lógica (1890-1897) \\
\hline & Ética (1890-1895) \\
\hline & Lógica y ontología (1897-1925) \\
\hline & Cosmología y teodicea (1897-1925) \\
\hline \multirow{2}{*}{ Dr. Bernal Zurita, Miguel } & Ética y derecho natural (1911-1924) \\
\hline & Lógica (1927-1931) \\
\hline \multirow{2}{*}{ Lc. Blanco Pérez, Francisco } & Historia natural (1881-1897) \\
\hline & Agricultura (1881-1887) \\
\hline \multirow{2}{*}{ Lc. Bravo Alfonso, José Ma } & Latín y castellano de Segundo (1876-1887) \\
\hline & Historia universal (1876-1897) \\
\hline \multirow{3}{*}{ Lc. Camacho Torres, José } & Ética (1870-1876) \\
\hline & Matemáticas (1870-1876) \\
\hline & Historia eclesiástica (1876-1887) \\
\hline \multirow{3}{*}{ Dr. Cañamache Marqués, José } & Teología dogmática (1887-1893) \\
\hline & Instituciones canónicas (1887-1894; 1901-1903) \\
\hline & Decretales (1887-1894; 1897-1915) \\
\hline \multirow{2}{*}{ Dr. Carrera Sanabria, Manuel } & Física y química (1911-1914 \\
\hline & Teología dogmática (1915-1931) \\
\hline \multirow{2}{*}{ Dr. Coronil Gómez, Juan Manuel } & Historia natural (1920-1921) \\
\hline & Ética e historia de la filosofía (1921-1924) \\
\hline Dr. Eijo Garay, Leopoldo & Lengua hebrea (1903-1905) \\
\hline García Falcón, Cristóbal & Matemáticas (18181-1887) \\
\hline \multirow{3}{*}{ Dr. García García, Joaquín } & Lógica $(1887-1890)$ \\
\hline & Historia de la filosofía (1867-1897) \\
\hline & Ética (1895-1897) \\
\hline \multirow{3}{*}{ Dr. Gil Álvarez, Jerónimo } & Ética e historia de filosofía (1913-1920) \\
\hline & Historia natural (1913-1920) \\
\hline & Instituciones de derecho (1920-1922) \\
\hline
\end{tabular}




\begin{tabular}{|c|c|}
\hline PROFESOR & MATERIA \\
\hline Dr. Gómez Saucedo, Mariano & Teología moral (1897-1919) \\
\hline \multirow{2}{*}{ González, Manuel } & Latín y castellano de Primero (1888-1889) \\
\hline & Historia sagrada (1888-1889) \\
\hline \multirow{3}{*}{ Dr. González Álvarez, José } & Ética e historia filosofía (1897-1898) \\
\hline & Auxiliar teología (1897-1898) \\
\hline & Matemáticas (1904-1911) \\
\hline Dr. González Marchán, Rafael & Teología dogmática (1911-1915) \\
\hline \multirow{4}{*}{ Dr. Holgado Yusta, José } & Auxiliar derecho canónico (1905-1910) \\
\hline & Instituciones derecho canónico (1915-1921) \\
\hline & Liturgia y teología pastoral (1918-1922) \\
\hline & Prelecciones del código (1920-1931 \\
\hline Dr. Iborra García, Juan Vicente & Teología moral (1876-1887) \\
\hline Dr. Insausti, Agapito & Canto eclesiástico (1897-1909) \\
\hline \multirow{3}{*}{ Dr. Jiménez Castro, Manuel } & Teología dogmática (1876-1880) \\
\hline & Sagradas escrituras (1898-1899) \\
\hline & Instituciones canónicas (1899-1918) \\
\hline \multirow{2}{*}{ López, Juan Antonio } & Catecismo (1880-1887) \\
\hline & Historia sagrada (1880-1887) \\
\hline Dr. López García, José & Sagradas escrituras (1897-1903) \\
\hline Dr. López Pérez, Antonio & Teología dogmática (1887-1911) \\
\hline Dr. López Porras, Antonio & Disciplina de concilio Trento (1858-1880) \\
\hline \multirow{2}{*}{ Luque Fontanilla, Manuel } & Latín y castellano (1881-1887) \\
\hline & Geografía (1881-1897) \\
\hline \multirow{2}{*}{ Dr. Marín Robayo, Francisco } & Auxiliar física y química (1914-1918) \\
\hline & Teología moral (1929-1931) \\
\hline \multirow{2}{*}{ Dr. Mateos Gago, Francisco } & Hebreo (1870-1887) \\
\hline & Griego (1870-1887) \\
\hline \multirow{2}{*}{ Minayo, Felipe } & Liturgia y cómputo eclesiástico (1888-1897) \\
\hline & Teología pastoral (1888-1897) \\
\hline Dr. Molina Arjona, Agustín & Teología dogmática (1881-1897) \\
\hline Dr. Montero Díaz, Ildefonso & Matemáticas (1911-1926) \\
\hline Lc. Montoto Laniella, Castor & Historia eclesiástica (1887-1898) \\
\hline \multirow{2}{*}{ Dr. Moreno Maldonado, José } & Decretales (1915-1920) \\
\hline & Teología moral (1919-1929) \\
\hline Lc. Moro Recio, Benito & Disciplina de concilio Trento (1887-1890) \\
\hline Moyennin, Juan María & Francés (1887-1897) \\
\hline
\end{tabular}




\begin{tabular}{|c|c|}
\hline PROFESOR & MATERIA \\
\hline \multirow{2}{*}{ Dr. Muñiz Pablos, Tomás } & Auxiliar de filosofía (1897-1898) \\
\hline & Instituciones de derecho (1901-1904) \\
\hline \multirow{2}{*}{ Dr. Muñoz Morón, José } & Historia natural (1897-1913) \\
\hline & Física y química (1897-1915) \\
\hline \multirow{6}{*}{ Dr. Muñoz Pabón Juan Francisco } & Interino de retórica y poética (1887-1888) \\
\hline & Latín de Tercero (1890-1891; 1892-1897) \\
\hline & Retórica-poética (1890-1891; 1892-1897) \\
\hline & Latín de cuarto (1893-1897) \\
\hline & Auxiliar de teología (1897-1898) \\
\hline & Sagradas escrituras (1902-1920) \\
\hline \multirow{2}{*}{ Lc. Ortiz de Urtarán, Ricardo } & Fundamentos de religión (1876-1881) \\
\hline & Lugares teológicos (1876-1881) \\
\hline \multirow{2}{*}{ Dr. Pabón Barquero, Andrés } & Historia eclesiástica (1914-1920) \\
\hline & Lengua hebrea (1914-1928) \\
\hline \multirow{4}{*}{ Dr. Peña Fernández, Manuel } & Griego (1887-1897) \\
\hline & Hebreo (1887-1897) \\
\hline & Arqueología sagrada (1887-1897) \\
\hline & Instituciones de derecho (1897-1902) \\
\hline \multirow{2}{*}{ Dr. Pérez Córdoba, Antonio } & Apología de la religión (1893-1897) \\
\hline & Patrología y elocuencia sagrada (1911-1922) \\
\hline Dr. Pérez Godoy, Silvestre & Disciplina concilio Trento (1890-1892) \\
\hline \multirow{6}{*}{ Dr. Pérez Gómez, José María } & Latín y castellano de Primero (1876-1881) \\
\hline & Historia sagrada (1876-1880) \\
\hline & Geografía (1876-1881) \\
\hline & Retórica y poética (1891-1892) \\
\hline & Historia de España (1881-1887) \\
\hline & Perfección latina (1881-1888) \\
\hline \multirow{5}{*}{ Dr. Rexach Cubero, Ramón } & Auxiliar de teología (1903-1905) \\
\hline & Patrología y elocuencia sagrada (1904-1911) \\
\hline & Historia eclesiástica (1904-1914) \\
\hline & Lengua hebrea (1911-1914) \\
\hline & Decretales (1911-1915) \\
\hline \multirow{2}{*}{ Dr. Roca Ponsa, José } & Cuestiones teológicas (1897-1931) \\
\hline & Teología dogmática (1897-1902) \\
\hline
\end{tabular}




\begin{tabular}{|c|c|}
\hline PROFESOR & MATERIA \\
\hline \multirow{4}{*}{ Dr. Rodríguez González, Man. } & Instituciones canónicas (1897-1914) \\
\hline & Física y química (1915-1916) \\
\hline & Teología dogmática (1922-1931) \\
\hline & Catequética y misionología (1929-1931) \\
\hline \multirow{4}{*}{ Dr. Rodríguez Sánchez, Man. } & Física y química (1887-1897) \\
\hline & Instituciones canónicas (1894-1897) \\
\hline & Decretales (1894-1897) \\
\hline & Derecho canónico (1897-1914) \\
\hline \multirow{2}{*}{ Dr. Roldán Barrios, Federico } & Instituciones de derecho (1904-1922) \\
\hline & Decretales (1915-1916) \\
\hline \multirow{2}{*}{ Dr. Roldán Castillo, Federico } & Arqueología sagrada (1901-1911) \\
\hline & Lengua hebrea (1905-1914) \\
\hline \multirow{2}{*}{ Dr. Romero Castaño, Cristobal } & Arqueología sagrada (1911-1913) \\
\hline & Historia natural (1911-1915) \\
\hline Dr. Romero Gago, Bartolomé & Decretales (1897-1911) \\
\hline \multirow{3}{*}{ Dr. Ruiz-Cabal, Rodríguez, Antonio } & Teología dogmática (1870-1876) \\
\hline & Instituciones canónicas (1876-1887) \\
\hline & Decretales (1876-1887) \\
\hline Dr. Ruiz López, Felipe & Instituciones dogmáticas (1880-1887) \\
\hline \multirow{2}{*}{ Sánchez López, Juan Bautista } & Geometría y trigonometría (1887-1895) \\
\hline & Historia natural (1887-1897) \\
\hline \multirow{2}{*}{ Dr. Sánchez Susillo, Ángel } & Instituciones de derecho (1915-1916) \\
\hline & Decretales (1916-1931) \\
\hline Lc. Sánchez Torres, Agustín & Sagradas escrituras (1876-1890) \\
\hline \multirow{2}{*}{ Dr. Sánchez Vázquez, Juan F. } & Lógica y ontología (1897-1927) \\
\hline & Cosmología y teodicea (1897-1927) \\
\hline \multirow{2}{*}{ Dr. Serra, Juan Bautista } & Teología moral (1887-1897) \\
\hline & Fundamentos de religión (1890-1893) \\
\hline Dr. Sierra Sánchez, Francisco & Disciplina del concilio Trento (1880-1897) \\
\hline \multirow{2}{*}{ Dr. Sancho Sorribas, Tomás } & Ética e historia de la filosofía (1897-1922) \\
\hline & Dialéctica práctica (1904-1907) \\
\hline \multirow{2}{*}{ Dr. Sanz Saravia, Juan Manuel } & Patrología y elocuencia sagrada (1897-1904) \\
\hline & Historia eclesiástica (1898-1904) \\
\hline \multirow{2}{*}{ Dr. Sebastián Bandarán, José } & Arqueología cristiana (1913-1926) \\
\hline & Historia eclesiástica (1898-1904) \\
\hline
\end{tabular}




\begin{tabular}{|c|c|}
\hline PROFESOR & MATERIA \\
\hline \multirow{2}{*}{ Tobar Marín, Manuel } & Liturgia y cómputo eclesiástico (1887-1888) \\
\hline & Ascética y mística (1887-1889) \\
\hline \multirow{2}{*}{ Dr. Torres Galeote, Francisco } & Auxiliar de filosofía (1897-1901) \\
\hline & Ética e historia de la filosofía (1901-1913) \\
\hline \multirow{5}{*}{ Lc. Torrado Marín, Antonio } & Latín y castellano de Primero (1887-1888) \\
\hline & Historia sagrada (1887-1888) \\
\hline & Latín y castellano de Segundo (1888-1893) \\
\hline & Historia de España (1888-1889) \\
\hline & Aritmética y álgebra (1889-1890) \\
\hline \multirow{5}{*}{ Dr. Vacas González, Juan Cris. } & Elocuencia sagrada (1887-1897) \\
\hline & Ascética y mística (1890-1897) \\
\hline & Disciplina del concilio de Trento (1895-1897) \\
\hline & Liturgia (1897-1918) \\
\hline & Teología pastoral (1897-1918) \\
\hline \multirow{3}{*}{ Vizcaíno Moya, Manuel } & Física y química (1870-1881) \\
\hline & Historia natural (1876-1881) \\
\hline & Agricultura (1876-1881) \\
\hline
\end{tabular}




\section{ANEXO SEGUNDO}

En este anexo ofrecemos la relación de todas las personas que compusieron el colegio de doctores en la época de Muñoz y Pabón, figurando entre ellos nuestro escritor ${ }^{91}$.

\section{COLEGIO DE DOCTORES DE LA FACULTAD DE TEOLOGÍA}

\begin{tabular}{|l|c|}
\hline NOMBRE & FECHA \\
\hline Abín Pinedo, Modesto & $1899-1931$ \\
\hline Arellano Santos, Antonio & $1915-1931$ \\
\hline Bernal Zurita, Miguel & $1925-1931$ \\
\hline Canamache Marqués, José & $1897-1912$ \\
\hline De Ardales, Juan Bautista (capuchino) & $1915-1931$ \\
\hline De San José Mariano (provincial franciscano) & $1897-1907$ \\
\hline DeValencina, Ambrosio (provincial capuchino) & $1897-1914$ \\
\hline Gómez Rodríguez, Manuel & $1925-1931$ \\
\hline Gómez Saucedo, Mariano & $1915-1931$ \\
\hline González Macías, Manuel & $1925-1931$ \\
\hline González Merchant, Rafael & $1903-1918$ \\
\hline Jiménez Castro, Manuel & $1897-1921$ \\
\hline López Pérez, Antonio & $1899-1914$ \\
\hline Muñoz Pabón, Juan Francisco & $1903-1920$ \\
\hline Pérez Córdoba, Antonio & $1897-1925$ \\
\hline Rodríguez Montero, Antonio & $1897-1898$ \\
\hline Romero Gago, Bartolomé & $1897-1931$ \\
\hline Sánchez Susillo, Ángel & $1921-1931$ \\
\hline Sevillano Moro, Aureliano & $1915-1922$ \\
\hline SánchezVázquez, Juan Flaviano & $1897-1931$ \\
\hline Santos Olivera, Balbino & $1924-1913$ \\
\hline
\end{tabular}

91 M. MARTIN RIEGO, La formación intelectual del clero. El seminario... o.cit., 184-185. 